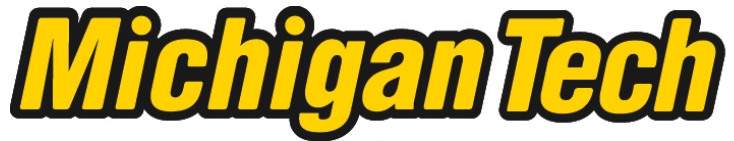 \\ Michigan Technological University Create the Future Digital Commons @ Michigan Tech
}

2015

\section{A FIELD INVESTIGATION OF COMPOSITE MUD BRICK COMPRESSIVE STRENGTH}

Kevin D. Hale

Michigan Technological University

Follow this and additional works at: https://digitalcommons.mtu.edu/etds

Part of the Civil Engineering Commons, Materials Science and Engineering Commons, and the Mechanical Engineering Commons

Copyright 2015 Kevin D. Hale

\section{Recommended Citation}

Hale, Kevin D., "A FIELD INVESTIGATION OF COMPOSITE MUD BRICK COMPRESSIVE STRENGTH", Master's Thesis, Michigan Technological University, 2015.

https://doi.org/10.37099/mtu.dc.etds/1000

Follow this and additional works at: https://digitalcommons.mtu.edu/etds

Part of the Civil Engineering Commons, Materials Science and Engineering Commons, and the Mechanical Engineering Commons 


\title{
A FIELD INVESTIGATION OF COMPOSITE MUD BRICK COMPRESSIVE STRENGTH
}

\author{
By \\ Kevin D. Hale \\ A THESIS \\ Submitted in partial fulfillment of the requirements for the degree of \\ MASTER OF SCIENCE \\ In Mechanical Engineering
}

MICHIGAN TECHNOLOGICAL UNIVERSITY

2015

(c) 2015 Kevin D. Hale 

This thesis has been approved in partial fulfillment of the requirements for the Degree of MASTER OF SCIENCE in Mechanical Engineering.

Department of Mechanical Engineering - Engineering Mechanics

\author{
Thesis Co-Advisor: $\quad$ Dr. Michele H. Miller \\ Thesis Co-Advisor: $\quad$ Dr. Ibrahim Miskioglu \\ Committee Member: Dr. Kari B. Henquinet \\ Department Chair: $\quad$ Dr. William W. Prebedon
}





\section{Contents}

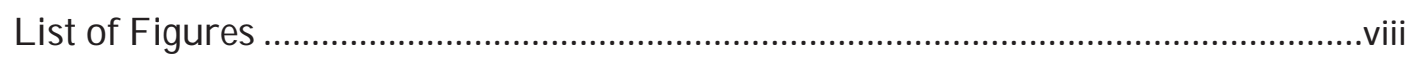

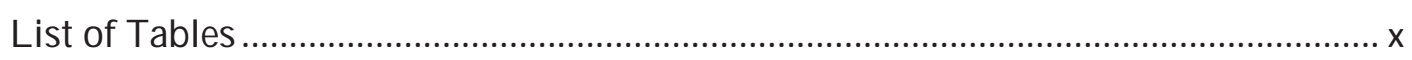

Acknowledgements ................................................................................................

Abstract...............................................................................................................

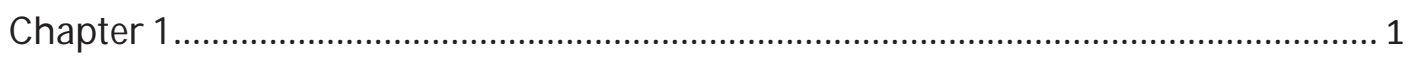

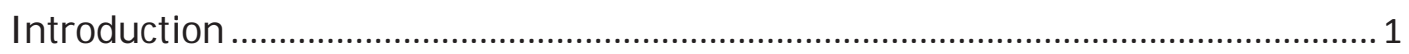

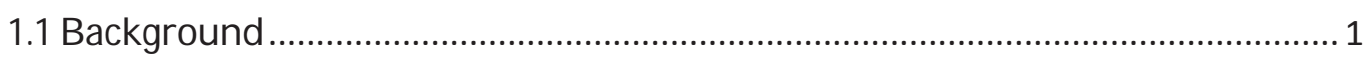

1.2 History of Earth Construction ....................................................................... 2

1.3 Composite Mud Bricks............................................................................................. 4

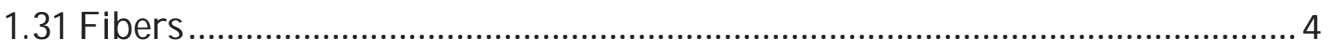

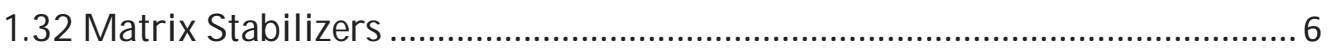

1.33 Chemical Coatings.............................................................................................

1.4 Field Tests........................................................................................................

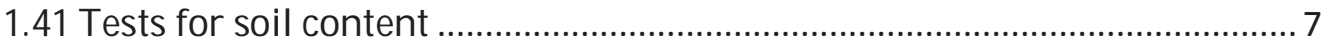

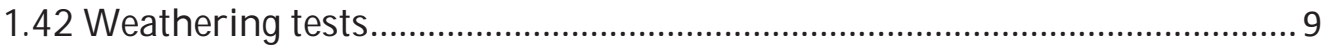

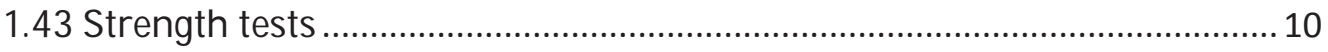

1.5 Current State of Earth Construction................................................................ 12

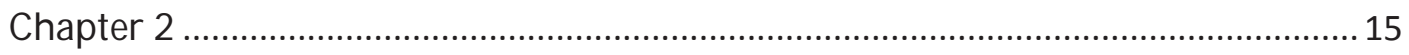

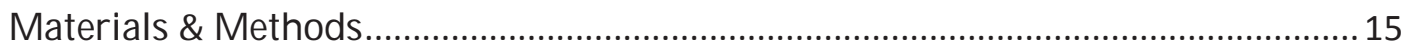


2.1 Traditional Brick Production............................................................................... 15

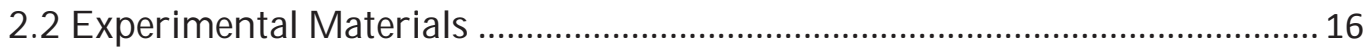

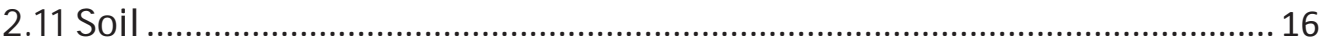

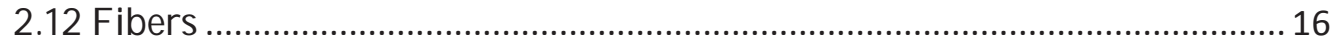

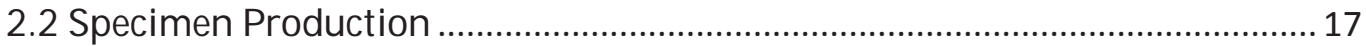

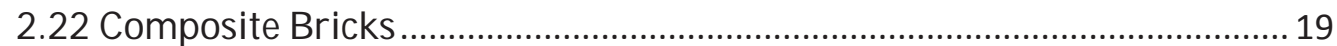

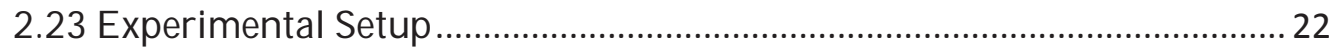

2.3 Experimental Methods........................................................................................ 27

2.31 Brick measurements ...................................................................................... 27

2.32 Applying load P ........................................................................................ 28

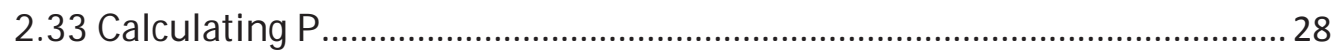

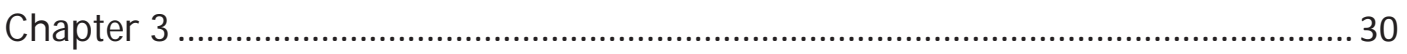

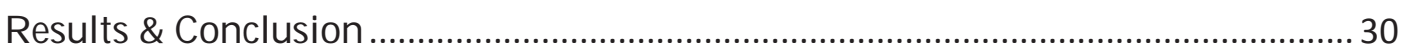

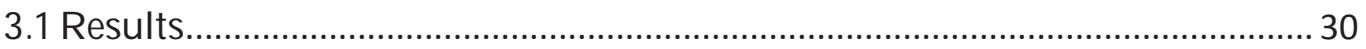

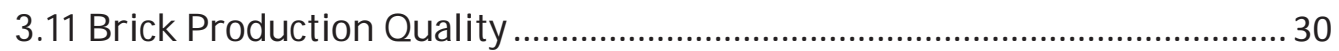

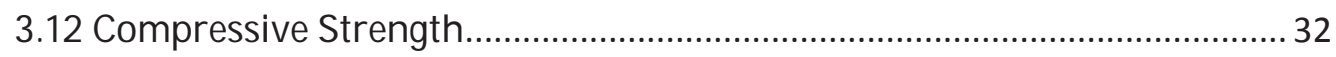

3.13 Feasibility of 3-point Bending Test............................................................ 44

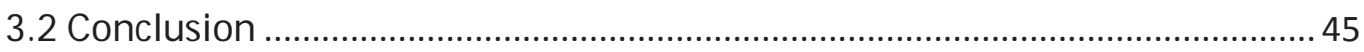

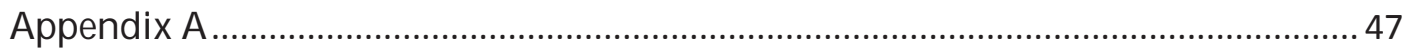

Experimental Details for Calculating Maximum Dry Density (MDD) at Optimum Moisture Content (OMC) …………………………………………………………... 47

Drop Ball Test and Soil Workability ..................................................................... 49

Evaluation of Field Tests............................................................................................ 51

Sedimentation in a bottle................................................................................... 51

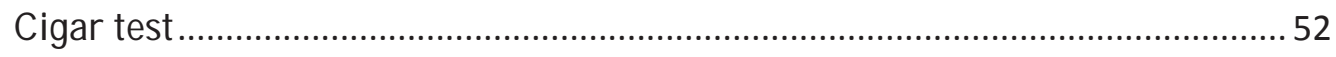




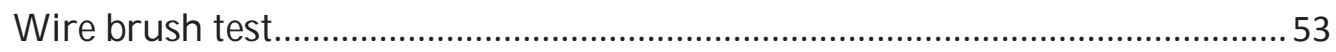

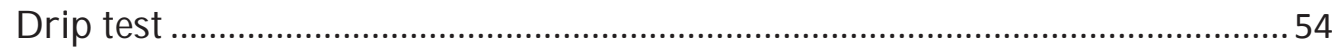

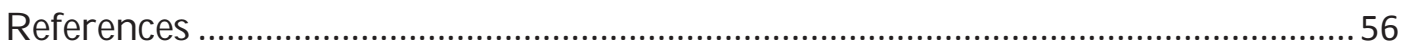




\section{List of Figures}

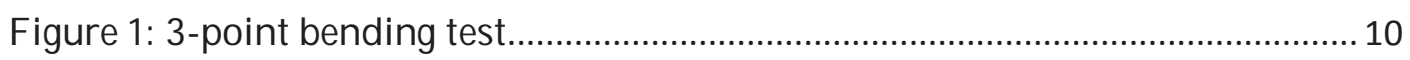

Figure 2: Arch behavior of a brick under 3-point bending compression .................. 11

Figure 3: Free body diagram of fictitious support beams used to model arch

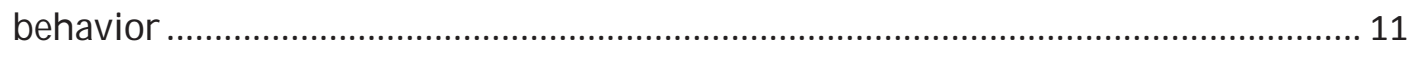

Figure 4: Termite hill soil with initial digging on left hand side ............................... 16

Figure 5: Three pronged fork made from bamboo and used to clean straw of blades

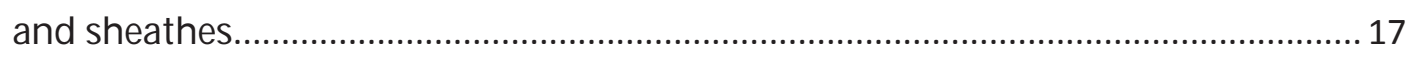

Figure 6: Cutting straw fibers.......................................................................... 17

Figure 7: Soil sieve made from chicken wire and tree branches............................... 19

Figure 8: Mixing of the soil, water and straw fibers................................................ 19

Figure 9: Wooden mold used to form the mud bricks .............................................. 21

Figure 10: The classification of brick quality............................................................. 22

Figure 11: First iteration of the 3-point bending test ................................................. 23

Figure 12: Basic schematic of the lever system ........................................................ 24

Figure 13: Cattle plow used to create the lever........................................................... 24

Figure 14: 19th century foot-powered band saw used as fulcrum and testing

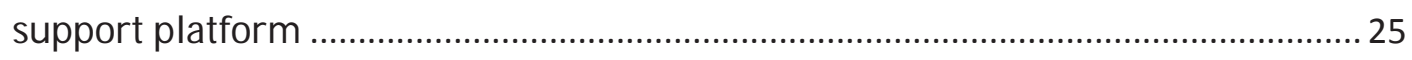

Figure 15: First iteration of 3-point bending lever system ...................................... 25

Figure 16: 3-point bending apparatus with extended lever......................................... 26

Figure 17: Final iteration of 3-point bending test apparatus ..................................... 27

Figure 18: Free body diagram of the lever with four buckets attached...................... 29

Figure 19: Compressive strength of no-crack bricks ................................................. 34

Figure 20: Average compressive strength of no-crack bricks for each testing

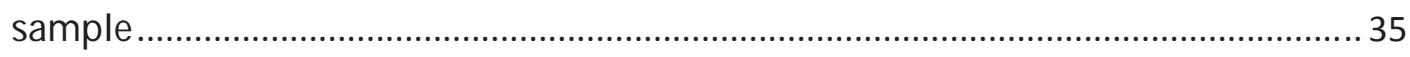

Figure 21: Compressive strength of no-crack and small crack bricks........................ 37 
Figure 22: Average compressive strength of no-crack and small crack bricks for

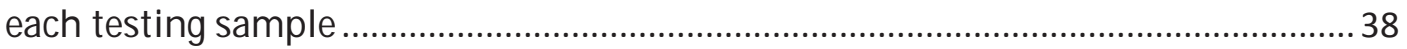

Figure 23: Compressive strength of all bricks tested ................................................ 40

Figure 24: Average compressive strength for all bricks in each testing sample...... 41

Figure 25: Container used to make MDD volume samples......................................... 47

Figure 26: Soil samples molded at various moisture content..................................... 48

Figure 27: Graph displaying optimum moisture content .......................................... 49

Figure 28: Drop ball test at 14\% moisture content..................................................... 50

Figure 29: Drop ball test at 16\% moisture content................................................... 50

Figure 30: Drop ball test at an OMC of 20\% …………………............................... 50

Figure 31: Drop ball test at 24\% moisture content ......................................................51

Figure 32: Wire brush with 3kg of weight attached.................................................... 53

Figure 33: Mud brick after receiving the wire brush test..............................................54

Figure 34: Experimental setup of drip test............................................................... 55 


\section{List of Tables}

Table 1: Brick production quality statistics for each type of composite produced.. 31 Table 2: Compressive strength of each composite calculated using no-crack bricks

only. 33

Table 3: Compressive strength of each composite calculated using no-crack and small crack bricks. 36

Table 4: Compressive strength of each composite calculated using all tested bricks

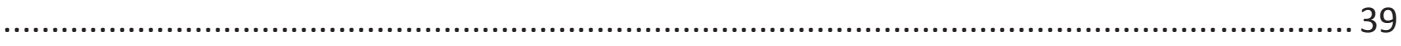

Table 5: Average mass and corresponding moisture content of samples for MDD

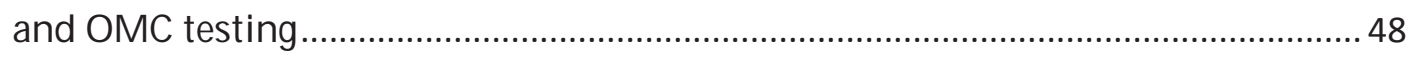

Table 6: Results from cigar test................................................................................ 53

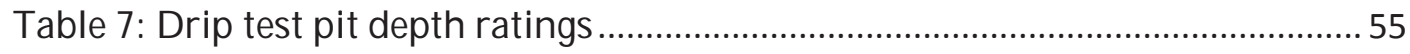




\section{Acknowledgements}

I would like to thank Dr. Michelle H. Miller and Dr. Ibrahim Miskioglu for their unwavering support and willingness to help me succeed. Their insightful and prompt guidance was essential throughout the entire process. I would also like to thank my students and friends Elias Lourenco Carina, Assane Amade Cabado, Ernesto Filimone Mahache and Acacio Mansur Heidar whose tireless efforts, dedication and knowledge were indispensable to the realization of this project. My thanks and appreciation go out to my committee member and Peace Corps Master's International program director Dr. Kari B. Henquinet who on short notice graciously provided essential feedback for improving this thesis. Last but not least I would like to thank all my friends and family who support me in everything I attempt throughout life may they become successes or failures. 


\section{Abstract}

It has been highlighted in numerous publications that in the field of earth construction there is a strong disconnect between experimental work in the laboratory and its application in the field. The current study attempts to help bridge this gap with a field test conducted in Nampula, Mozambique. Mud bricks were made with a simple hand mold and reinforced with bamboo and straw fibers. Fibers were cut into lengths of $3 \mathrm{~cm}$ and $6 \mathrm{~cm}$ while being mixed in fractions of $0.125 \%, 0.25 \%$ and $0.50 \%$ by weight and compressive strength was measured using an application of the 3-point bending test. It was found that neither straw nor bamboo increased the composite brick's strength and in fact a decrease of strength was recorded. An increase in brick strain energy density was observed with increasing fiber fraction. 


\section{Chapter 1}

\section{Introduction}

\subsection{Background}

The current study was conducted as part of the Peace Corps Master's International program in which the author served two years as a Peace Corps volunteer in Nampula, Mozambique while simultaneously conducting field research in partial fulfillment of a Master's of Science in Mechanical Engineering with Michigan Technological University. During this time the author lived in a mud brick community of approximately 2,000 people and it was observed that many homes had collapsed over the years due to brick deterioration caused by weathering.

Climatically Mozambique has a tropical wet and dry climate characterized by six months of dry season and six months of rainy season. The average rainfall in Nampula is approximately $1008.5 \mathrm{~mm} /$ year [1]. The use of mud bricks in areas of heavy rainfall can cause homes to degrade and ruin prematurely. This forces homeowners' to continuously focus on housing repairs and ultimately the entire reconstruction of a home. It was observed that many homeowners' began reconstruction after roughly seven to eight years and needed one to two years for completion depending on outside circumstances such as weather and other personal factors.

The constant attention required for maintaining the stability of mud brick housing consumes pertinent time that could be utilized to develop other aspects of one's life such as food security and income development which all relate to health, life expectancy and emerging out of poverty. With this in mind it was decided to 
investigate the current field of earth construction and methods therein for improving the strength properties of mud bricks.

\subsection{History of Earth Construction}

The use of earth as a building material reaches far back in humanity. One of the earliest known examples are the Zhoukoudian caves. Discovered in the 1920's southwest of modern Beijing and dating back anywhere from 600,000-780,000 years ago, they represent one of the earliest known instances of earth being used for home construction [2]. The first evidence of earth being formed into a brick was discovered in the upper Tigris basin and dates back as far as $7500 \mathrm{BC}$ [3]. Since then, earth bricks have been used extensively throughout history to help create masterful structures such as the Great Wall of China, temples for Ramses II in Egypt, the Ishtar Gate in Babylon and countless pyramids in Mesoamerica [2].

Requiring only soil and water, mud bricks are one of the simplest building materials. Historically it was learned through trial and error that a soil must contain clay in order to form a cohesive brick. It is now recommended in the literature that soils contain a clay content of anywhere from $10-22 \%$ depending on the researcher proposing the mixture [4]. Composite mud bricks are soil-water mixtures that are combined with an additive such that a given property of the composite brick will improve. Animal hair, animal manure and various plant fibers are historically common additives.

As civilizations developed so did the materials and engineering involved with construction. Countries with access to such development abandoned earth construction as an archaic method while countries without access continued to depend upon earth construction as the only means to housing. This change of direction in developed countries caused the focus of academic research to follow suit. Therefore the remaining half of the world living void of access to advanced materials continued to rely on earth construction as the principal means of housing while it persisted in its rudimentary undeveloped form. 
Only in recent decades has earth construction received a renewed attention by the academic community [5]. This is due to the common knowledge that populations are growing, resources are finite and relying on energy intensive materials such as steel and concrete is not practical. Environmentally sustainable solutions must be researched. In response, countries such as France, New Zealand, Australia, Germany, Spain, Peru, Zimbabwe and the state of New Mexico have all put forth national documents regarding the use of natural earth as a construction material. There have also been recommendations put forth for the continent of Africa by CRATerre [4], [6].

Unfortunately, the new found interest in earth construction is highly focused toward its application in developed countries. The large majority of people currently struggling with the inherent difficulties of living in hand-constructed earth built homes are essentially neglected. This is demonstrated by the quantity of laboratory based research that does not carry any direct application in the field at a community based level. Experiments which are executed using sophisticated laboratory equipment that operate at high precision under fastidiously controlled conditions are not transferable to the field in which conditions are highly dynamic and processes are performed using simple hand tools. Therefore field testing methods must be developed that facilitate the advancement of earth construction in underdeveloped countries.

To support this cause many authors have contributed greatly by publishing detailed works that list methods for field testing and recommended values one should obtain [7]-[9]. There have also been strides in developing computer aided predictive models for determining mechanical properties of composite bricks [8], [9]. However, often times these field tests only determine basic soil properties and recommended methods and results are vague or contradict each other [4]. There are very few field tests meant to quantify the overall strength and durability of a mud brick which is imperative to the process of developing an improved version. One field test that has been recommended for determining compressive strength is the 3-point bending test, yet there still does not exist any literature detailing its use in the field leaving its feasibility unknown [10]. Similar arguments can be made 
with regard to the true effects of reinforcing fibers when composite bricks are produced under field conditions. Therefore the purpose of the current research is to provide such a study and lead the way for future experiments to advance the work.

\subsection{Composite Mud Bricks}

A composite mud brick is a soil-water mixture (the matrix) combined with an additive such that the new composite material has improved mechanical or chemical properties. For clarity the matrix additives will be divided into three categories: fibers, matrix stabilizers and chemical coatings.

\subsection{Fibers}

Fibers are typically produced in short $(1-5 \mathrm{~cm})$ prismatic shapes from materials of high tensile strength that can be thought of as ideally inextensible. They are cut to predetermined lengths and mixed with the matrix at specified proportions based on weight or volume. Mixing fibers by weight is more common than volume and fiber fractions often stay below $1 \%$ with $0.50 \%$ being advised as an upper limit by some [11], [12]. However there still do not exist standard values advised for fiber fractions and must therefore continue to be studied on an individual soil/fiber basis until a consensus can be reached.

The predominant incentive for mixing fibers into the mud brick matrix is to increase the compressive and shear strengths of the composite brick. However, it should not be assumed that this is accomplished due to an inherently large compressive strength directly contributed by the fiber. Quantitatively, the Young's modulus of the matrix is combined with the Young's modulus of the fiber through one of the accepted methods such as Voigt, Reuss or Hill to create an improved Young's modulus of the composite [8]. Qualitatively, however, when a matrix undergoes compressive stress the fibers reinforce the composite through the absorption of energy and distribution of the applied compressive stress; largely 
supported by high fiber tensile and shear strengths. Therefore the most substantial compressive strength gains are made when fibers are laid perpendicular to the applied loading. Random fiber organization, which is often encountered in the field, diminishes this effect. Many researchers have noted that the addition of fibers also increases the ductility of the brick and decreases post-peak strength loss [13]-[18].

Fibers can be generally classified in two categories: man-made or natural. Common man-made fibers are glass, polypropylene, polyester, polyethelene, nylon, steel and polyvinyl alcohol. Natural fibers may include coir, sisal, palm, jute, flax, bamboo, straw and sugar cane [13], [14], [15]. There has also been research in the use of polymers, tire shreds and rice fibers [16], [17]-[24].

Straw is a common natural fiber due to its worldwide abundance and ease of which it can be harvested and gathered. There is evidence of its use both in biblical and Roman times. Unfortunately, even with straw's ubiquitous and long standing use as a reinforcing fiber experimental results are still inconclusive on its true effect. Bouhicha et al. [18] tested the uniaxial compressive strength of four different soils and found that compressive strength increased by $10-20 \%$ with straw fiber fractions up to $1.5 \%$ and decreased by as much as $40 \%$ thereafter. Contradicting these results Sukru et al. [11] tested uniaxial compressive strength of four similar soils reinforced with up to $3.84 \%$ straw fiber and did not note any increase of compressive strength. The authors concluded that straw fibers should not be added above $0.05 \%$ by weight. The disparity in these results regarding the effect of straw fibers is one focus of the present study.

A review of common natural fibers and factors affecting their properties such as aspect ratio, tensile strength and cellular makeup can be found in Rowell et al. [19]. 


\subsection{Matrix Stabilizers}

The principal difference between a fiber and a matrix stabilizer is the composition of the material being added to the matrix. Fibers tend to be prismatic, uniform in aspect ratio and remain as a distinct material when combined with the soil matrix. Stabilizers, on the other hand, are often crushed to fine particle distributions and thoroughly mixed throughout the matrix creating a homogenous material and losing their distinction. The purpose of matrix stabilizers are to increase material strength of the composite and diminish the effects of weather erosion.

Lime and cement are two of the most researched stabilizers due to both their deep historical relevance and superior properties as a building material [20]. They have been studied for thermophysical, acoustic, strength and weathering properties [21], [22], [23]. Other researched stabilizers are gypsum, basaltic pumice, fly ash, boron waste and crushed coconut shells [8], [17], [21], [24]-[32].

\subsection{Chemical Coatings}

The quantity of research on chemical coatings does not rival that of fibers or stabilizers. The primary goal of coating a brick or fiber with a given chemical is to decrease moisture absorption levels. For a fiber the decrease of moisture absorption will minimize the swelling and contracting that takes places during mixing and curing. Diminishing the swelling and contracting of the fiber due to water absorption will minimize the void created at the fiber matrix interface [15]. This can ultimately lead to improved bonding strength at the interface and decrease the probability of fiber pullout. Similarly, the goal of coating the brick in a given chemical is to decrease moisture absorption and ultimately minimize degradation due to weathering. Researched chemicals that have shown promising results are MEDALATEX, soluble sodium silicate, water based silicone emulsion, solvent based oligomeric siloxane and a tree resin [23], [25], [26]. It should be mentioned that in many countries cement is also coated on the outside of an earth built structure for added durability against weather. 


\subsection{Field Tests}

In order to support the development of earth construction in underdeveloped nations many researchers have put forth various field testing methods to help interpret a given soil's potential as a building material [7]-[9]. These field tests mainly gauge soil content through measurements of soil cohesion, dry and wet consistency, water retention, shrinkage, compactibility and dry strength. There also exist tests for soil erosion, water absorption and depth of water penetration that help predict durability to weathering.

The focus of the current study is on dry compressive strength, however, during initial research investigations many other field tests were experimented. These tests are listed below and also serve as a relative overview of the field testing methods available in the literature. However, as these tests do not directly pertain to the study at hand their results are not listed in the main body. A more detailed outline regarding experimental results for some of the following field tests can be found in Appendix A.

\subsection{Tests for soil content}

Touch, smell and wash

By far the simplest of the field tests for soil identification, the touch, smell and wash test is meant to give a general idea of sand vs. clay content. Simply take a small amount of soil and rub it between your fingers and in the palm of your hand feeling for grit and density. Once a general feel is decided, lightly wet the soil and continue to inspect its texture. Also, give the soil a light smell. If a musty odor is observed the soil contains organic material and should not be used for building. If the soil begins dense and becomes contrastingly smooth when wet then it has a high silt/ clay content. If the soil stays coarse, then it is primarily sand. Once finished, gently wash your palm. If the soil leaves a stain, then a high clay content 
is further supported. If the soil washes off easily, then it is predominantly sand [27].

Sedimentation in a bottle

A common and straight forward soil test is sedimentation in a bottle. The test is meant to give the user an idea of the proportions of gravel, sand, silt and clay content within a soil. While the procedure varies slightly from author to author, the idea is the same. Fill a jar with one part soil and one part water. Shake the jar vigorously and allow the soil to settle for thirty minutes to an hour. The larger particles (gravel) will sink to the bottom while the less dense particles (silt and clay) will layer on top. From examining the thickness of the layers one can gauge the soil's particle distribution [7].

\section{Cigar test}

The cigar test, also known as the sausage test, is a quantitative method for judging a soil's cohesiveness which also indicates clay/ silt content. The basic idea is to wet the soil until it just reaches the sticky point and then form it into a cigar of $3 \mathrm{~cm}$ in diameter. Place the cigar on a table. Next, keeping the cigar horizontal, slowly slide one end of the cigar off the edge of a table. Continue to slide the cigar until it breaks. Measure the length of the broken piece and the size will give an indication of soil cohesion. Some proposed values are that if the broken cigar is less than $5 \mathrm{~cm}$ the soil is too sandy, if it is greater than $15 \mathrm{~cm}$ the soil is too clayey and values in between are appropriate for earth construction [27].

Textural classification

One of the more detailed field methods for soil identification, Rowell details a step by step guideline for determining the texture class of a soil which can then be used to gauge particle-size distribution using the USDA system [28]. The test is performed by first wetting a soil to the sticky point and rolling it into a $2.5 \mathrm{~cm}$ ball. The ball is then rolled into a short thick cylinder, long thread and eventually the 
thread is formed into a ring. Throughout the process the soil is inspected for cracking and if any of the tasks cannot be completed then the soil is thereby identified. There are twelve levels of identification ranging from sand to loam to clay with variations in between.

Drop test

The drop test is a qualitative method for gauging water content of a soil-water mixture. It is performed by taking a ball of the mixed soil and dropping it onto a hard surface from a height of approximately one meter. If the ball smashes like a pancake then it has too much water. If the ball disintegrates upon impact or breaks into many small pieces then it does not have enough water. If the ball splits into three or four large pieces then it is at the optimum moisture content (OMC) [29].

\subsection{Weathering tests}

Drip test

Developed at Deakin University by Yttrup et al. [30] and later advanced by Frenchman [31], the drip test is a feasible method for investigating a brick's durability against erosion caused by rain drops. The test is executed by releasing $100 \mathrm{~mL}$ of water from a height of $400 \mathrm{~mm}$ onto a brick inclined at $27^{\circ}$. The water should discharge over a period of 20-60 minutes. Once completed, the pit depth created by the drip test can be measured by a rod $3 \mathrm{~mm}$ in diameter and the brick can be categorized as non-erosive, slightly erosive, erosive or very erosive based on the pitting depth.

Wire brush test

The wire brush test is performed by stroking a metal wire brush which has been loaded with $3 \mathrm{~kg}$ of weight across the top of a brick for 60 cycles over the duration of approximately one minute (one cycle is brushing forward and back). Afterward, the soil is removed and the brick is re-weighed. The African Regional Organization 
for Standardization (ARSO) recommends that for a one story dwelling exposed to weathering the percentage loss of mass should not exceed 10\% [32].

\subsection{Strength tests}

\section{3-Point bending}

Proposed by Morel \& Pkla, the 3-point bending test is the only field method for quantitatively determining the compressive strength of a brick [10]. Depicted in Figure 1, execution of the test is analogous to that of a laboratory controlled 3point bending test and the compressive stress at failure is calculated using Equation 1 which only relies on knowledge regarding brick geometry and the applied force $P$.

$$
\sigma_{c}=\frac{P}{4 h l} \sqrt{1+\frac{L}{4 e^{2}}}
$$

where

$\sigma_{c}$ : Compressive strength

$P$ : Force of the applied weight

$l$ : Width of the test brick

$L$ : Distance between bottom support bars

$e$ : Distance between bottom and top bars

$2 h$ : Thickness of the arch

This approach to compressive strength is considered an indirect method because it is not derived from classical Strength of Materials theory $\vec{\sigma}=\frac{M \vec{y}}{I}$. In short, the authors claim that the compressive stress is primarily transmitted to the lower support bars through an arch effect

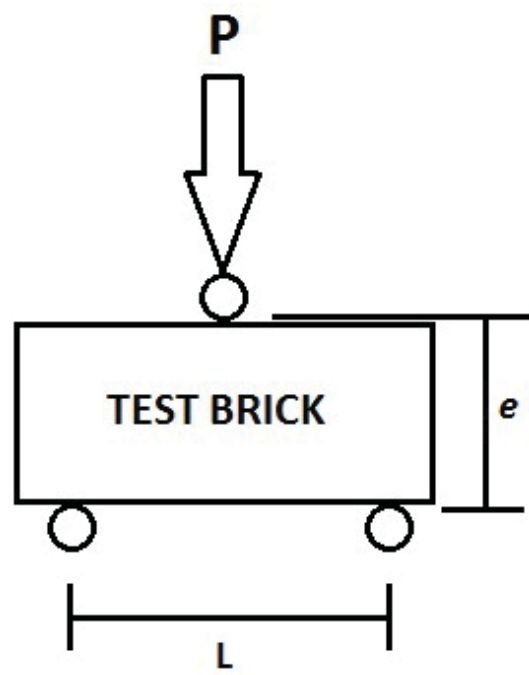

Figure 1: 3-point bending test. 
shown in Figure 2. They then model these arches with fictitious beams of thickness $2 h$, width $l$ (width of the brick) and length $\lambda$ as shown in Figure 3 . The approach is built around the assumptions that the fictitious beams receive the uniform stress due to $\mathrm{P}$ and rupture in compression immediately before brick failure begins at point $\mathrm{M}$. Therefore, by calculating the compressive strength of the fictitious support beams the compressive strength of the brick can be accurately estimated. The accuracy of this approach has been validated in the laboratory by Morel \& Pkla and Morel et al. against the bending-traction formula, RILEM testing and direct compression testing [10], [33].

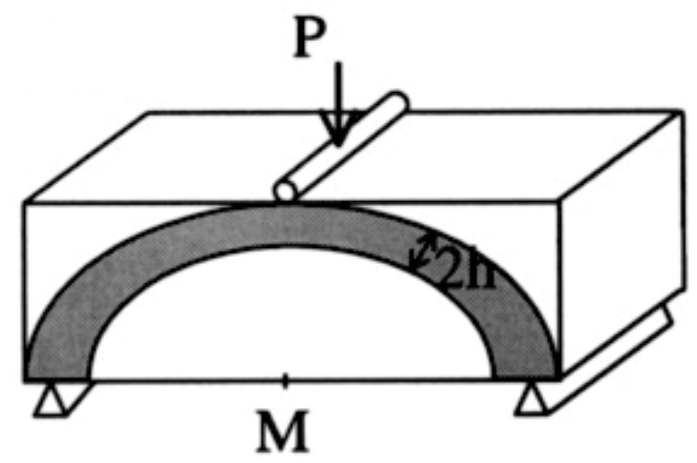

Figure 2: Arch behavior of a brick under 3-point bending compression. $2 \mathrm{~h}$ is the thickness of the support beams and therefore the arch as well.

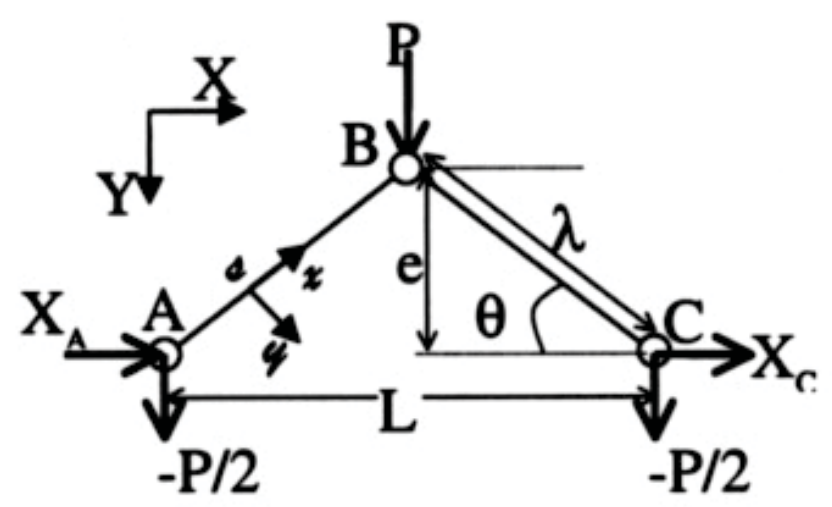

Figure 3: Free body diagram of fictitious support beams used to model arch behavior. Bars are AB and BC.

The 3-point bending test is claimed to be a field appropriate method for determining compressive strength without the need for sophisticated equipment; that failure can be achieved by simply stacking a few bags of cement or other bricks 
for the applied load [10], [33]. However, there is yet to be any work documenting its implementation in the field. The present study intends to fill this gap.

\subsection{Current State of Earth Construction}

The field of earth construction finds itself as the focus for the solution of two equally important problems: creating dependable housing for the impoverished of underdeveloped countries and enabling sustainable growth in developed countries with booming development and finite resources. In the latter there has been an abundance of successful research including studies in foundation engineering, airstrip and helipad design, earthquake engineering, railway embankments and building masonry [12], [13], [14], [24], [26], [34], [35]. In the former, however, research has been stagnant and unapproached. What disassociates the two fields is not their ultimate goal; each field works toward the improvement of soil reinforcement. Instead, what separates them is the manner in which this goal can be achieved and the way in which it must be pursued.

In developed nations earth construction is a solution for the future. If implemented, it will be supported through organized funding and production. Materials will be quality controlled and labor will be executed by trained professionals. With an intended use and implementation of this nature, it is perfectly acceptable that all research supporting earth construction is performed within laboratories under fastidiously controlled conditions. However, this laboratory focused approach does not suffice and is not applicable to underdeveloped nations.

For the millions currently living in earth built homes, earth construction is not a potential solution for the future in which the weaknesses can be meticulously studied in laboratories for improvement. It is quite the opposite. Earth construction is an everyday means to survival. It is the way in which families build homes and often the only option available to them. Techniques are those which have been passed down through generations of experimentation, materials and tools are sparse and access to financial or human capital is often nonexistent. The 
life cycle of a project lives entirely within and at the community level. Therefore it is evident that the approach to researching solutions for the underdeveloped world cannot be the same as for the developed world. Solutions in the underdeveloped world must be accessible at the community level. They must be intended for immediate use and have tangible value. Procedures must already be proven and tested in the field, not solely experimented under laboratory controlled conditions.

In 1994 well known authors Houben and Guillard stated that "laboratory tests are irrelevant for mud bricks, but that is all that exists" [29]. Nearly twenty years later the journal of Building and Construction published a review of 190 papers in the field of soil reinforcement stating that, "In spite of the quantity of research conducted...there are still no scientific standard[s] or techniques for real field projects" [13].

Countless field tests have been developed to gauge soil composition and soil properties yet in a community accustomed to building from earth for generations, choice of an appropriate soil is not where their expertise lack. In an overview of earthen architecture Avrami et al. stated, "there is virtually no correlation between field and laboratory testing" and that "greater correlation between lab and field are needed...for determining which laboratory analyses are necessary or relevant to a particular situation" [36].

With these statements in mind the goal of the present research is twofold: to investigate an appropriate field method for increasing mud brick compressive strength while simultaneously conducting a feasibility study on the implementation of the 3-point bending test under true field conditions. It was decided to investigate fibers as opposed to stabilizers or chemical coatings for the following reasons: In Mozambique common matrix stabilizers such as lime, gypsum and basaltic pumice are not readily available. Furthermore, the chemical coatings most often researched in the literature are manufactured items and therefore represent an additional expense not suitable for community level adoption. Fibers, on the other hand, can be cut from essentially any plant that grows in abundance and are typically easier to produce in high volume than matrix 
stabilizers which often entail pulverizing an initially dense material into fine particle distributions. Furthermore, fibers can be controlled in both fiber fraction and fiber length which allows for a more detailed analysis ultimately creating greater opportunity for insight into any results that may be attained. Therefore in the present study bamboo and straw were chosen as reinforcing fibers. Both plants grow prodigiously in Mozambique and also serve as appropriate contrasts to each other. Bamboo has a much stronger compressive and tensile strength than straw while also possessing a rougher fiber surface which contributes to increased shear strength at the fiber-matrix interface. Finally, the current literature lacks research concerning bamboo's field use in soil bricks and is inconclusive regarding that of straw. To contribute to this knowledge composite bricks were produced containing fibers cut in lengths of $3 \mathrm{~cm}$ and $6 \mathrm{~cm}$ to evaluate the effect of fiber length. Fibers were added in weights of $0.125 \%, 0.25 \%$ and $0.50 \%$ to further investigate the lower bounds of fiber fractions. All results were compared to baseline bricks which did not include any reinforcing fibers whatsoever. 


\section{Chapter 2}

\section{Materials \& Methods}

\subsection{Traditional Brick Production}

The traditional brick making method in Mozambique only utilizes two tools, a garden hoe for digging and a wooden mold for brick formation (Figure 9). A garden hoe is chosen strictly due to availability of tools. Once a soil is dug the water is added directly at the digging site and mixed using the garden hoe and the stomping of feet. The water content is controlled qualitatively through texture but in essence is added until a maximum soil workability is achieved. There is not much attention paid to oversaturation of the soil. After the water and soil have been mixed bricks are formed using the wooden mold and laid out in the sun to dry. In a four man team a full day's work can produce up to 1,000 bricks. A mason may also be hired to make bricks at a wage of 1 metical/ brick (3\$/brick). In Mozambique mixing fibers or other matrix stabilizers was not observed.

Throughout the current study effort was made to follow the traditional brick making process. Only a garden hoe was used for digging and a locally made wooden mold was used to form the bricks. As an extra precaution a soil sieve was created to facilitate fiber mixing. The water content was controlled using the drop test. 


\subsection{Experimental Materials}

\subsection{Soil}

In Mozambique it is considered common local knowledge that making bricks from soil on and around a termite hill provides for the most durable building material. Researchers have also noted that termite hill soil is strong against rain erosion which may possibly be due to a non-ionic

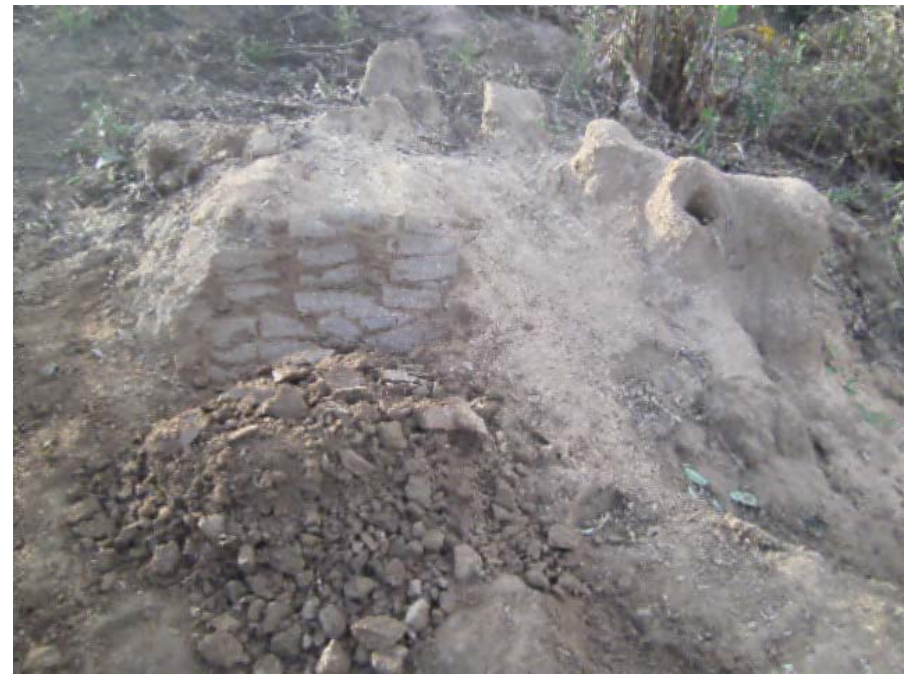

Figure 4: Termite hill soil with initial digging on left hand side. cellulose polymer actively secreted by the termites themselves [29]. Unfortunately, there is not any published literature that addresses the use of termite soil as a building material and how this polymer may serve as a matrix stabilizer. Therefore, to further this knowledge the current study used soil from a termite hill that was chosen by local masons and was actively being used to construct a community church. Figure 4 shows the termite hill. Sedimentation in a bottle, the cigar test and other identification methods unanimously indicated an extremely clayey soil.

\subsection{Fibers}

Straw was chosen as a fiber material due to its abundance in the region and the current literature's inconclusive results regarding its effect as a reinforcing fiber. Bamboo was also chosen for its extraordinarily high tensile strength, proven ability in cement matrices and its prodigious supply in Northern Mozambique [37], [38]. Furthermore, there is very little if any literature experimenting its use as a 
reinforcing fiber in soil bricks and was therefore chosen here. Attempts were made to choose stalks of both straw and bamboo similar in age since this can affect the plants cellular make up and mechanical properties [19].

\subsection{Specimen Production}

\subsection{Fibers}

Straw

Upon gathering straw the top and bottom of the stalks were cut to remove grains, roots and facilitate uniformity in fiber diameter. Any blades and sheathes were also removed leaving the bare stalks. In order to remove the blades and sheathes with maximum efficiency a local Mozambican hand tool that resembles a three pronged fork was utilized and is depicted in Figure 5. The hand tool is made by taking a short piece of bamboo and splitting the top half into three pieces. Stones or other dense material is then wedged in between the

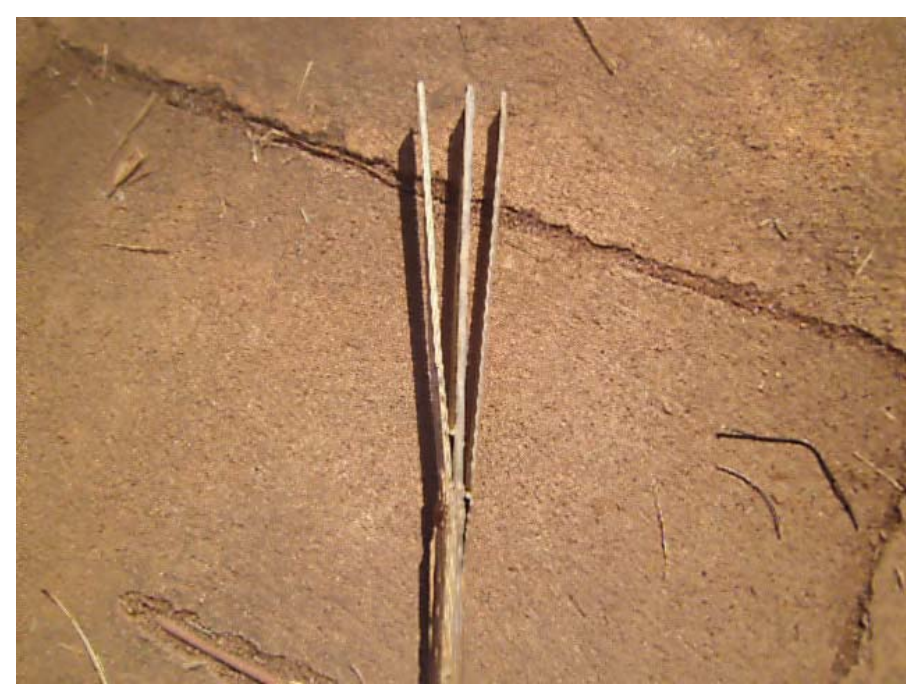

Figure 6: Three pronged fork made from bamboo and used to clean straw of blades and sheathes.

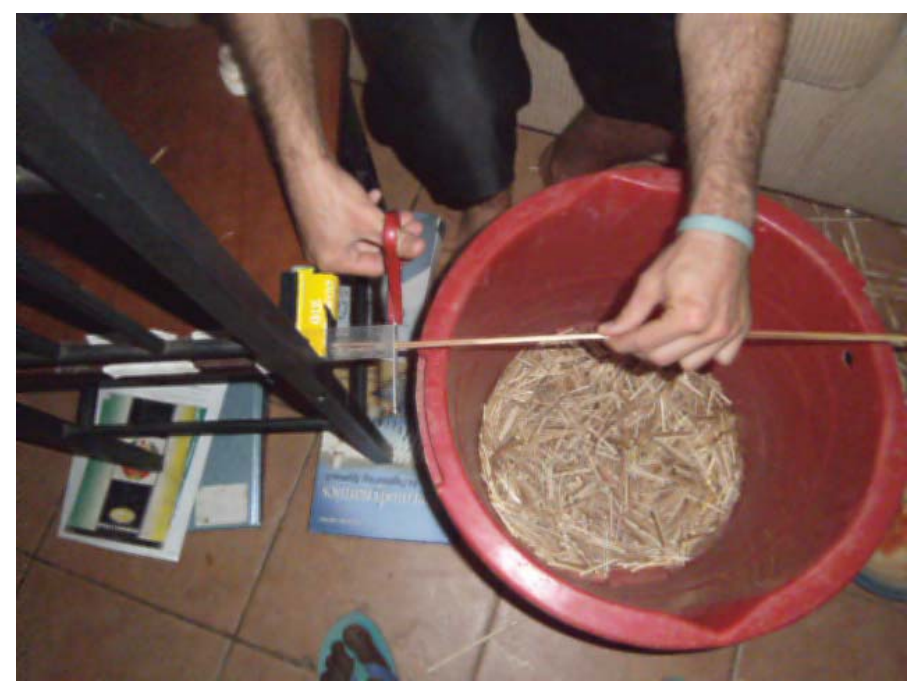

Figure 5: Cutting straw fibers. prongs to create separation. To remove the blades and sheathes a bundle of straw is held vertically and quickly combed up and down with the fork until clean. This 
method proved incredibly efficient and did not damage the actual stalk of the straw. Any leftover material was removed by hand until the stalk was completely bare.

Upon cleaning the straw stalk, fibers were then cut using a ruler, scissors and large bucket as shown in Figure 6. Fibers were cut in lengths of $3 \mathrm{~cm}$ and $6 \mathrm{~cm}$ with an average diameter of $0.3 \mathrm{~cm}$. It was found that cutting stalks in groups of three minimized time without losing accuracy or being too rigid for the scissors to penetrate. Using a machete was also experimented for cutting the straw into fibers. While this method increased the number of stalks cut at a time it led to inaccurate fiber lengths and many fibers being catapulted into the distance and lost, ultimately deeming the method inefficient.

Bamboo

Bamboo was gathered, cleaned and cut for uniformity analogous to the straw stalks. To create the fibers the bamboo stems were first cut into pieces of approximately 1 meter in length. Afterward, the stems were spliced longitudinally creating two halves. This process was continued until individual sticks of bamboo sufficiently thin for fiber cutting were created. The bamboo fibers were then made by cutting the bamboo sticks in $6 \mathrm{~cm}$ lengths. Due to bamboo's inherently higher compressive strength as a material, scissors could not be used to cut the fibers and a bench grinder was utilized. For safety reasons this method did not permit bamboo to be cut in fiber lengths of $3 \mathrm{~cm}$. The average diameter of the bamboo fibers was $0.24 \mathrm{~cm}$. 


\subsection{Composite Bricks}

Soil preparation

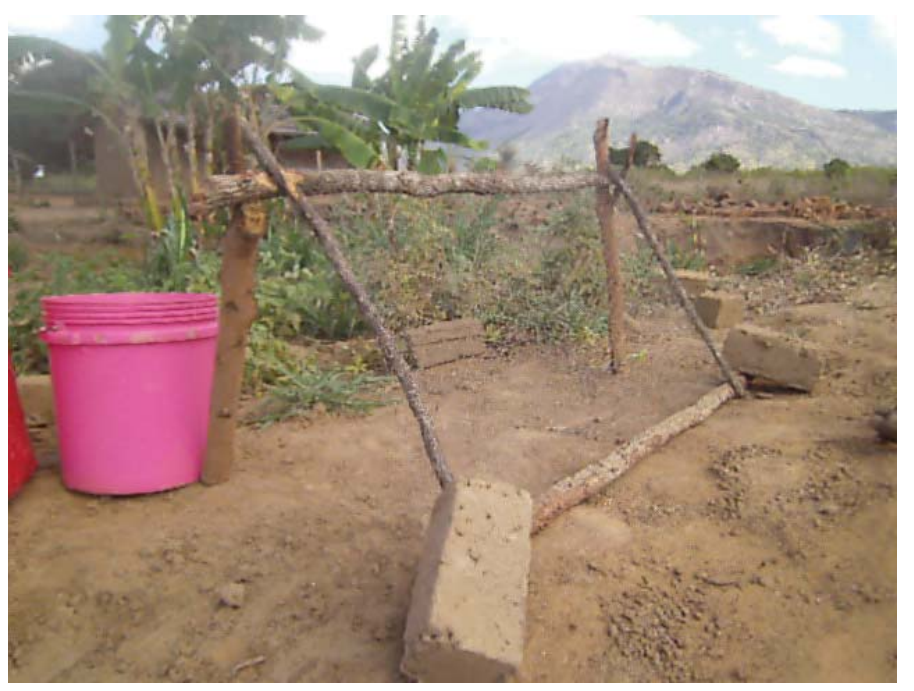

Figure 7: Soil sieve made from chicken wire and tree branches.
Soil was dug from the termite hill using metal garden hoes. Once dug the garden hoe was used to pulverize the soil into smaller clods. To further facilitate fiber-soil mixing and decrease the probability of lumps within the composite brick matrix the soil was passed through a $1 \mathrm{~cm}$ sieve made from tree

branches and chicken wire as depicted in Figure 7. In the traditional process of digging Mozambicans do not pulverize or pass the soil through any sieves.

Fiber mixing

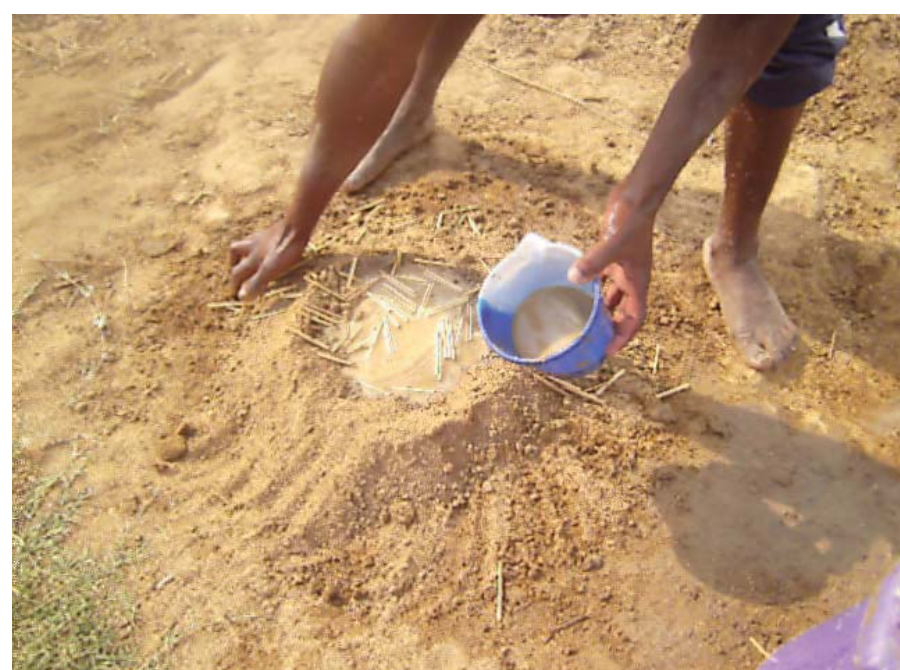

Figure 8: Mixing of the soil, water and straw fibers.
Through experimentation it was found that the optimal method in which to mix the soil and fibers was by hand in dry soil proportions of 10 L. The dry soil measured $1.297 \mathrm{~kg} / \mathrm{L}$ and fibers were therefore prepared and separated into bags of 0.016 $\mathrm{kg}, 0.032 \mathrm{~kg}$, and $0.064 \mathrm{~kg}$ for testing dry soil weight

fractions of $0.125 \%, 0.25 \%$ and $0.50 \%$ respectively. Before adding water, each $10 \mathrm{~L}$ 
volume of soil was mixed by hand in a large bucket with the appropriate fiber weight for a given test. The dry materials were mixed until a general uniformity was achieved. Afterward the dry materials were poured out and the soil-fiber mixture was formed into a volcano as seen in Figure 8. Water was then slowly poured inside the crater of the volcano while being mixed and kneaded thoroughly by hand with constant attention paid to the homogeneity of both the soil-fiber mixture and the soil-water mixture.

During preliminary experimentation it was found that the maximum dry density (MDD) of the soil corresponded to an optimum moisture content (OMC) of $20 \%$. Soil samples at the OMC were then subjected to the drop test in order to record their behavior upon impact. This analysis allowed the drop test to be used on each soil mixture during field testing to confirm water content before forming the brick. An outline of the experimental details used for calculating the MDD and OMC can be found in Appendix A.

Brick formation

Upon achieving an appropriate composite mixture, bricks were formed using the wooden hand mold shown in Figure 9. The composite mixture was filled into the mold and compacted by hand with attention paid to the corners of the mold. Once the mold was full, a wet hand was used to softly brush and smooth over the exposed surface of the composite mixture. To form the bricks the mold is carefully laid face down on a flat surface and then slowly lifted up leaving the formed brick while taking care not to stretch the brick upon release.

Throughout the entire process the brick mold should be kept submerged in clean water while not in use. After forming each brick the mold needs to be rinsed thoroughly with clean water, removing all leftover mud. Failure to do either of these will cause the newly formed brick to stick to the mold upon exit and sustain deformations when formed. 


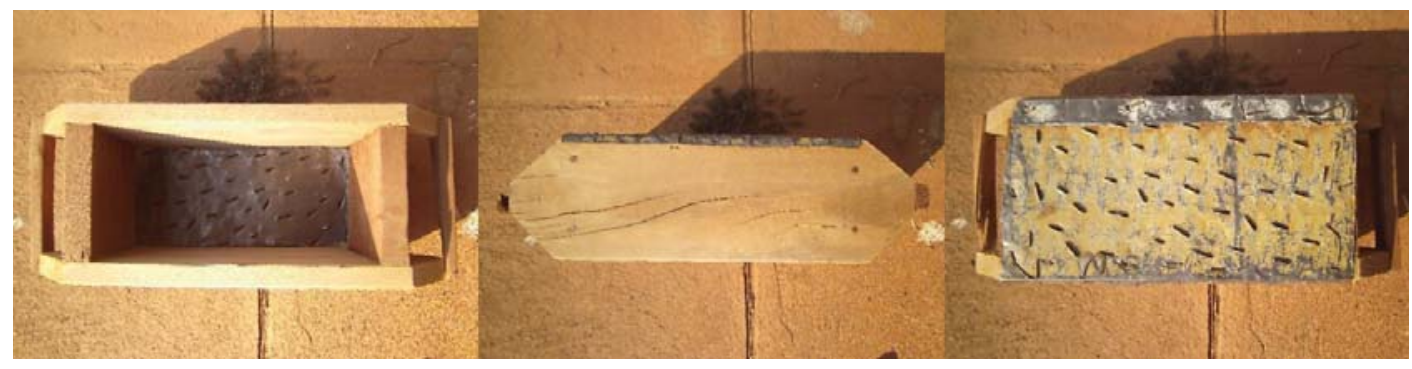

Figure 9: Wooden mold used to form the mud bricks. Top (left) side (center) and bottom (right) are shown. Mold has dimensions of 232x111.5x113.5mm (LxWxH).

Upon formation bricks were laid on a flat surface in an open area for drying and covered with straw to minimize the temperature gradient from the sun that can increase fractures during curing. This effect is also more pronounced in bricks made from soils with significant clay contents. During curing, bricks were inspected daily and left outside for an average of 7-10 days depending on daily temperatures and cloud cover. Upon curing, bricks were stored indoors for an additional 7-10 days before being tested.

Throughout the entire brick production process statistics were recorded regarding brick quality by categorizing the finished bricks into one of five groups depending on the number of fractures that appeared during curing. This organization allowed for further insight into the overall efficacy of brick production under field conditions.

The quality groups were defined as no-crack, small crack, moderate cracks, substantial cracking and completely fractured. A brick was defined as small crack if there existed the appearance of any fracture whatsoever. Small crack bricks typically only had one fracture across the middle of the top face. If a fracture was judged to have a substantial depth or width it was categorized as moderate. If the brick had multiple moderate cracks that raised doubt regarding the overall strength then its category was raised to substantial. Bricks that separated during curing or broke into two upon being dropped from a height of $1 \mathrm{~m}$ were categorized as completely fractured. Only bricks that qualified as no-crack, small crack and moderate cracks were used for testing. Examples of these categories can be seen in Figure 10. 


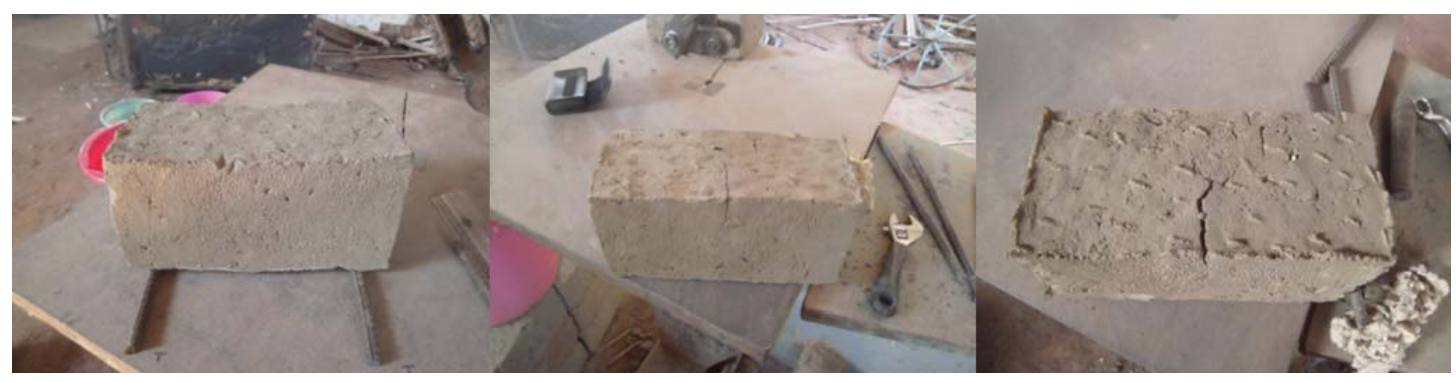

Figure 10: The classification of brick quality. A no-crack brick (left), a small crack brick (center) and a moderate crack brick (right).

It was found that brick strength did decrease as the quantity of cracks increased, however, the decrease in strength was not significant. It was also observed that the total number of usable bricks increased substantially with the use of fibers. Complete results are listed in Table 1 of Chapter 3.

\subsection{Experimental Setup}

3-point bending test apparatus

The 3-point bending test is referenced in the literature as an easy field method for calculating the compressive strength of a brick using simple weights such as other bricks or bags of cement [27], [10]. It is said that by using this method compressive strength can be found with an applied force 80-150 times less than what is needed for failure under uniform compression [33]. In congruence with these statements initial trials of the 3-point bending test were done according to the diagram in Figure 11. The bottom support bars and the top load bearing bar were made from steel rebar donated by a local road construction team. The steel rebar had a diameter of $10 \mathrm{~mm}$ and the applied weight $\mathrm{P}$ was provided by stacking other mud bricks on top of the test brick as depicted in Figure 11. Unfortunately, initial attempts revealed that this simple approach would be unable to produce 
repeatable results given the high force requirements for testing these bricks. One principal issue was the inability to balance the applied weight on the top bar. Individual bricks cannot be stacked sufficiently high to supply the necessary compressive force without tipping and adding additional contact forces to the test brick. To remedy this and following additional guidelines from the literature, a plate was placed on the top bar to allow for stacking a column of bricks. For additional support, guide wires were also connected to the plate in an attempt to maintain its balance during loading.

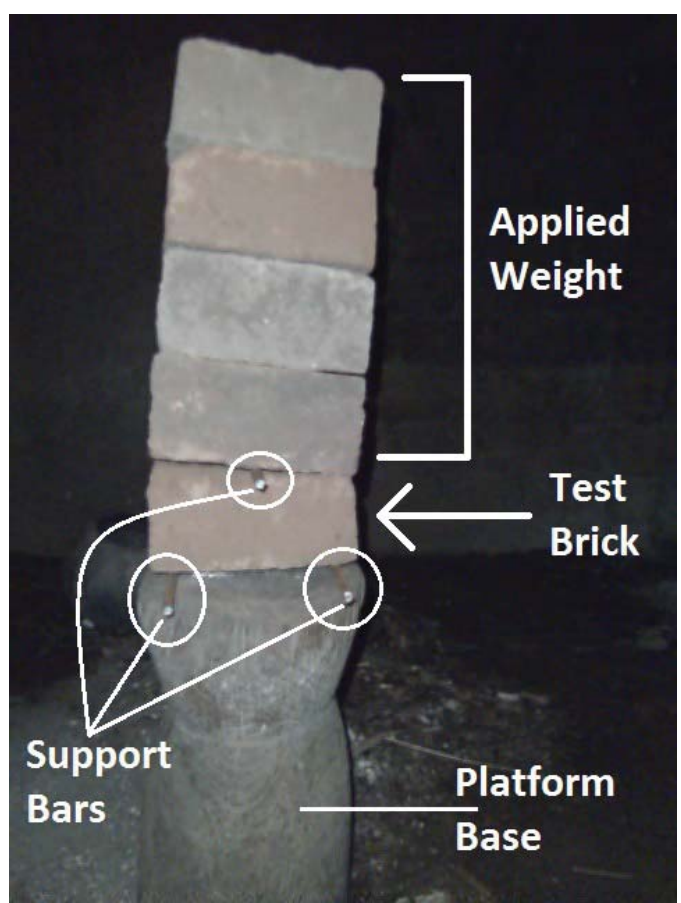

Figure 11: First iteration of the 3-point bending test.

However, once again the instability of the

applied weight was an issue and in no way was this simplistic approach to the 3point bending test realistic. Finally, using the common value of $2 \frac{\mathrm{N}}{\mathrm{mm}^{2}}$ for hand formed mud bricks and an average weight of $6 \mathrm{~kg} /$ brick it is straightforward to determine that it would be necessary to stack upwards of 50-60 bricks in order to achieve failure. Therefore through rudimentary testing it has been thoroughly concluded that the straightforward approach proposed for the 3-pont bending test in field applications is not feasible.

Construction of the lever system

To remedy the aforementioned issues it was decided to construct a lever system that would apply the load P. The use of a lever not only increases the stability of our applied load but it also allows for a lower external force when the equivalence of lever moments is utilized. With the presumption of forces being applied perpendicular to moment arms, the force applied to the test brick becomes 
proportional to the ratio of $\frac{r_{1}}{r_{p}}$ as defined in Figure 12. Therefore the longer the lever arm is, the lower the external force necessary to reach brick failure.

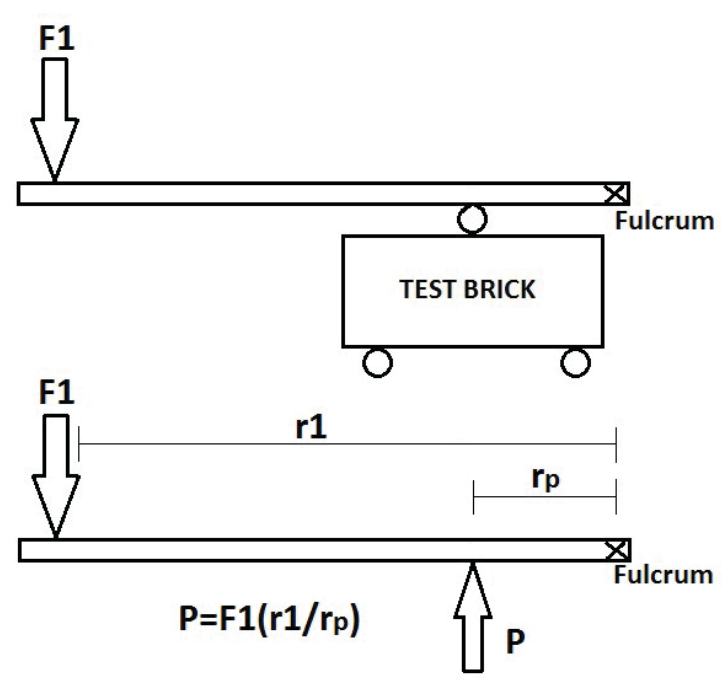

Figure 12: Basic schematic of the lever system. Brick and lever shown with externally applied force (top), free body diagram of the lever (bottom).
Materials for creating the lever system were adapted from an abandoned $19^{\text {th }}$ century foot-powered band saw and a manually driven cattle plow. The lever arm was created by removing the handle from the cattle plow shown in Figure 13. The cattle plow handle was made from steel with dimensions of 985x30x10 mm. The band saw shown in Figure 14 served as the fulcrum and provided the support platform for performing the compression tests. The fulcrum was chosen to be located at the band saw's blade-guide post and the lever was attached using a single $16 \mathrm{~mm}$ bolt. A full depiction of the actual lever system can be seen in Figure 15.
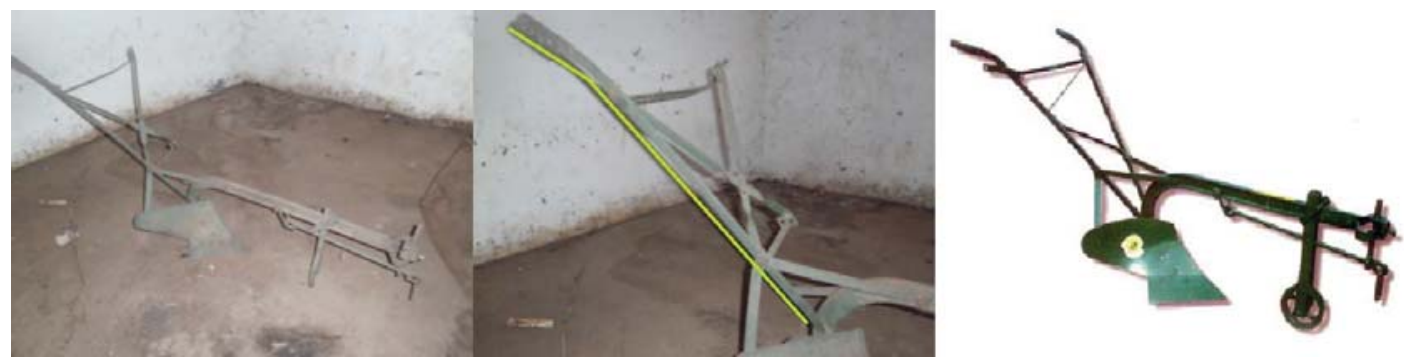

Figure 13: Cattle plow used to create the lever. The original plow is pictured (left) with the handle highlighted (center) and a digital version of a comparable plow (right). 

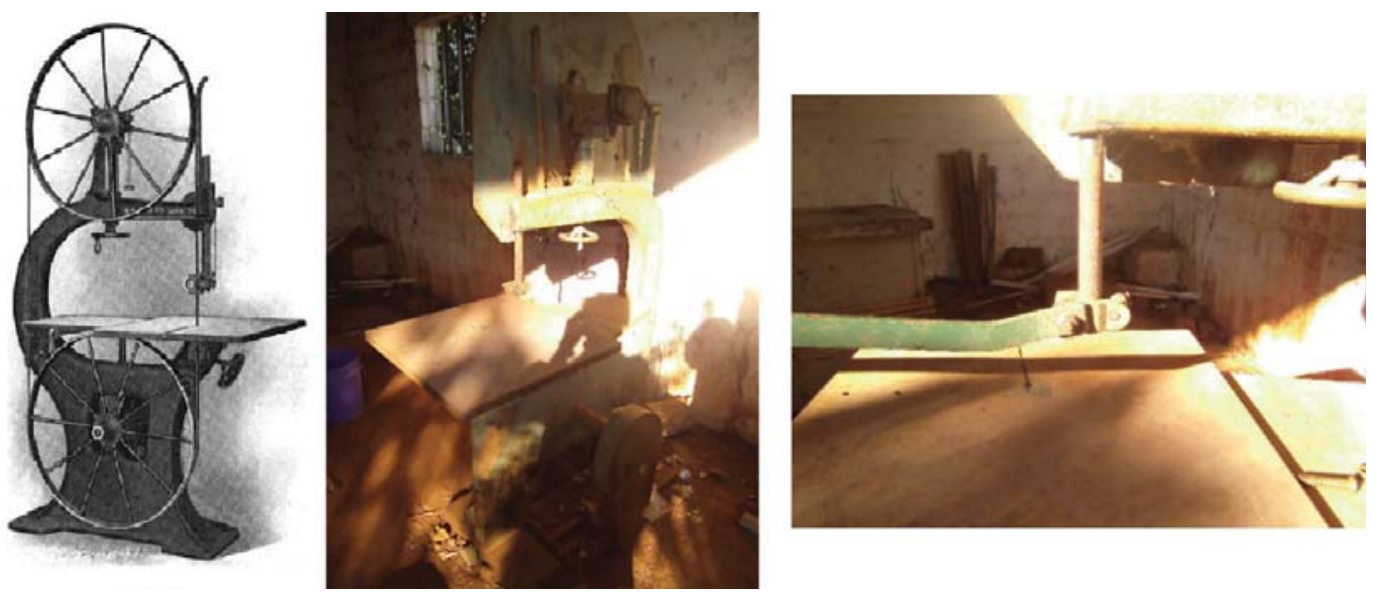

Figure 14: 19th century foot-powered band saw used as fulcrum and testing support platform. A digital image of a comparable 19th century band saw is pictured for clarity (left) [39] alongside the actual band saw used (center) and a photo of the blade-guide post with lever attached (right).

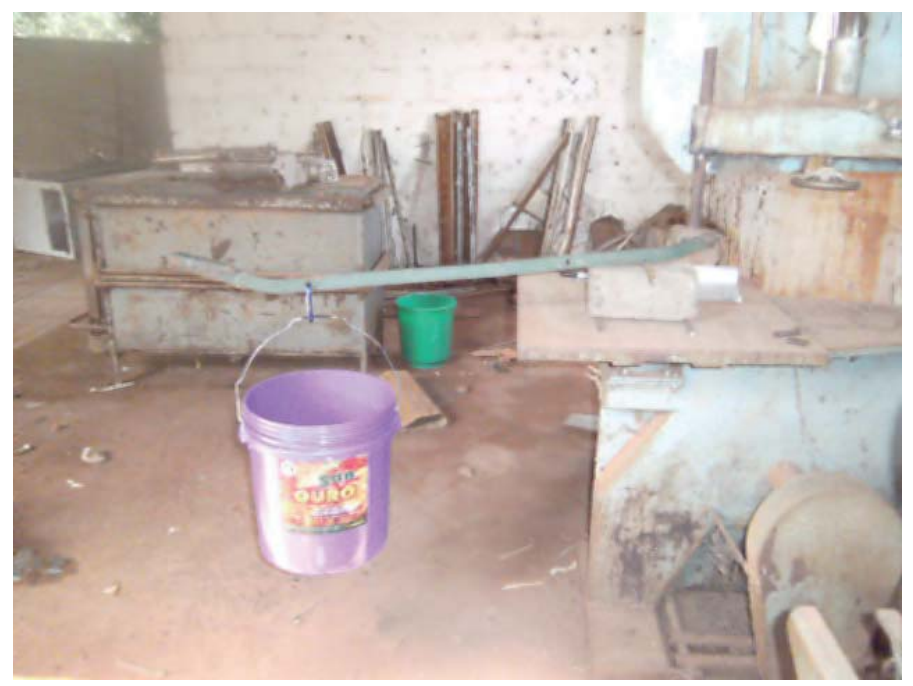

Figure 15: First iteration of 3-point bending lever system.

\section{Lever system modifications}

During initial test runs it was observed that the current lever could only support up to two $20 \mathrm{~L}$ buckets which did not provide the force necessary to induce brick failure. After analyzing materials available it was decided that the appropriate method was to extend the current lever arm by utilizing the second handle to the cattle plow. Due to the cattle plow's symmetry the handles were able to be attached utilizing their original bolt pattern and were joined by two $14 \mathrm{~mm}$ bolts. Figure 16 depicts the new lever system and the bolts joining the two handles. 


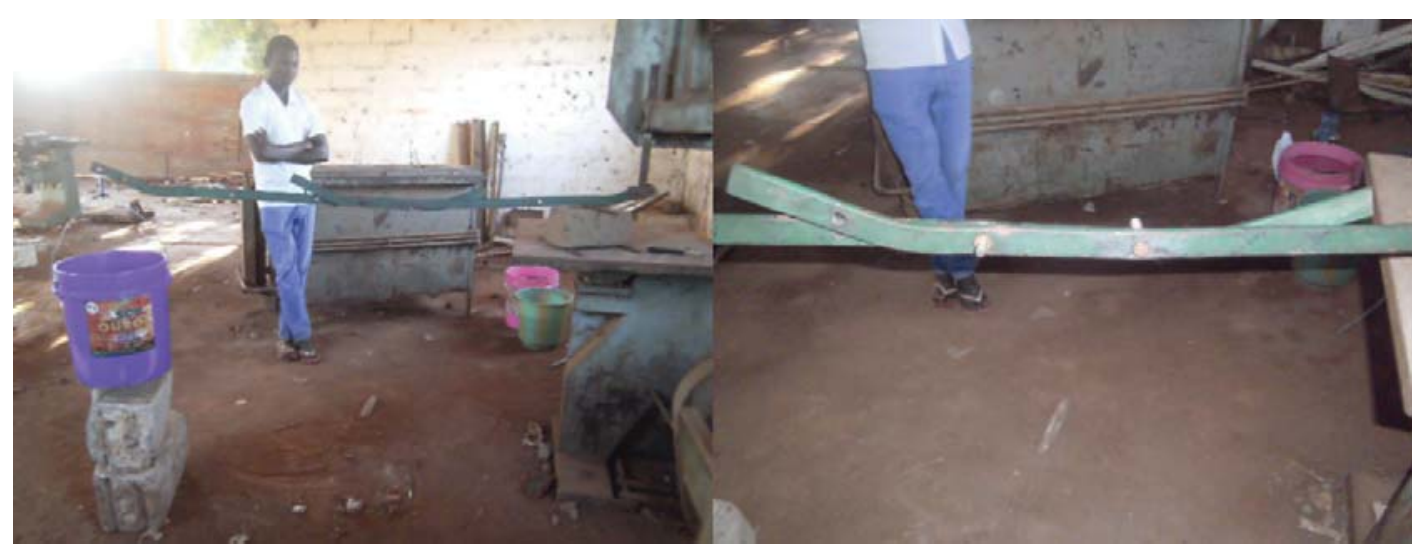

Figure 16: 3-point bending apparatus with extended lever. Testing apparatus (left) and image showing the bolts joining the plow handles (right).

An extended lever arm made it possible to attach up to four $20 \mathrm{~L}$ buckets which proved sufficient weight for obtaining brick failure. However, after further experimentation another problem was encountered. Multiple buckets (and specifically the bucket at the greatest distance from the fulcrum) began to twist the lever and bend it transversely in both the horizontal and vertical planes. Using small angle approximation it was estimated that the transverse bending in the horizontal plane had an angle of roughly $30^{\circ}$. The transverse bending in the vertical plane caused significant plastic deformation in the lever arm that ultimately needed to be hammered straight on repeated occasions. The focal point of the transverse bending for both planes occurred in the lever roughly $35 \mathrm{~cm}$ from the fulcrum where there existed an open bolt hole from the plow handle's original bolt pattern.

To remedy these problems it was decided to increase the lever arm's moment of inertia which would thereby diminish the bending moment. To accomplish this two pieces of steel rebar were attached to each side of the lever at the point in which it was bending. The steel rebar was in pieces of $63 \mathrm{~cm}$ and $30 \mathrm{~cm}$ in length. One piece of each length was attached to each side of the lever arm and secured using $2 \mathrm{~cm}$ elastic rubber tie downs. With additional testing the tie downs proved incapable to withstand the tension caused by the bending moment and snapped. 
The steel rebar was then welded onto the lever which endured for the remainder of testing. The final iteration of the lever system is shown in Figure 17.

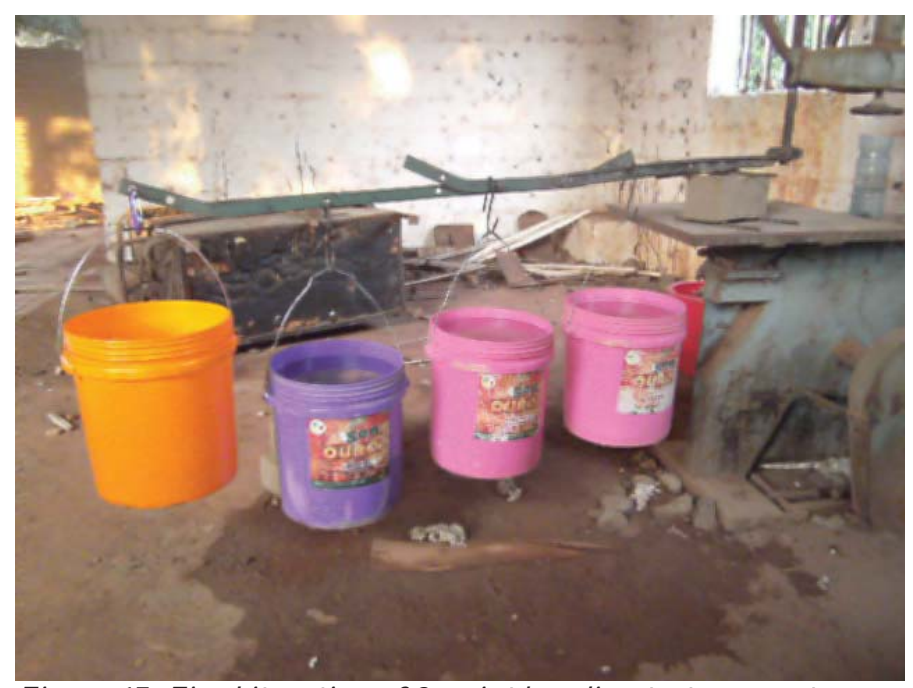

Figure 17: Final iteration of 3-point bending test apparatus.

\subsection{Experimental Methods}

\subsection{Brick measurements}

Throughout testing the distance between the bars $L$ was fixed to facilitate simplicity of procedure and uniformity of results. L was initially set at $190 \mathrm{~mm}$ but during preliminary test runs it was found that the bottom corners of the brick were chipping before brick failure was reached. To alleviate the stress on the corners the support bars were moved inward to a distance of $180 \mathrm{~mm}$ and a significant decrease in the number of fractured corners was observed.

The values l, e and $r_{p}$ were re-measured for every test run. To account for any tapering or sweeping of the brick the width l was taken as the average of four measurements; two on each end of the brick with one in the top half and one in the bottom half. All measurements were done with a standard $30 \mathrm{~cm}$ ruler of $1 \mathrm{~mm}$ graduations. 


\subsection{Applying load $\mathrm{P}$}

To apply the load buckets were attached to the lever at fixed distances and slowly filled with known volumes of water. Filling the buckets with known volumes of water allowed the applied force to be controlled in a straightforward manner while only using material readily available in the majority of field conditions.

During testing the buckets were placed at distances of $r 1=513 \mathrm{~mm}, r 2=$ $863 \mathrm{~mm}, r 3=1225 \mathrm{~mm}$ and $r 4=1586 \mathrm{~mm}$ as shown in Figure 17. Buckets were attached in order of increasing distance from the fulcrum. The first two buckets were pre-filled with $20 \mathrm{~L}$ of water and attached to the lever at distances of $513 \mathrm{~mm}$ and $863 \mathrm{~mm}$ respectively. The first two buckets contributed respective stresses of $0.3787 \frac{\mathrm{N}}{\mathrm{mm}^{2}}$ and $0.6371 \frac{\mathrm{N}}{\mathrm{mm}^{2}}$ at point $\mathrm{P}$ as calculated by Equation 1 . The third bucket was pre-filled with $5 \mathrm{~L}$ and increased in $5 \mathrm{~L}$ portions $\left(0.226 \frac{\mathrm{N}}{\mathrm{mm}^{2}}\right)$ until failure was reached. If brick failure had still not been obtained the fourth bucket

was attached empty and filled in $2 \mathrm{~L}$ increments $\left(0.117 \frac{\mathrm{N}}{\mathrm{mm}^{2}}\right)$. Buckets were filled by hand at a rate of approximately $2 \mathrm{~L} / \mathrm{min}$ and if brick failure occurred then bucket filling immediately stopped and volumes were recorded. This procedure varied slightly and was altered as necessary based on failure trends of the given test being performed. Bricks were also studied briefly upon failure for fiber distribution within the matrix.

\subsection{Calculating $P$}

A free body diagram of the four bucket method is shown in Figure 18. 


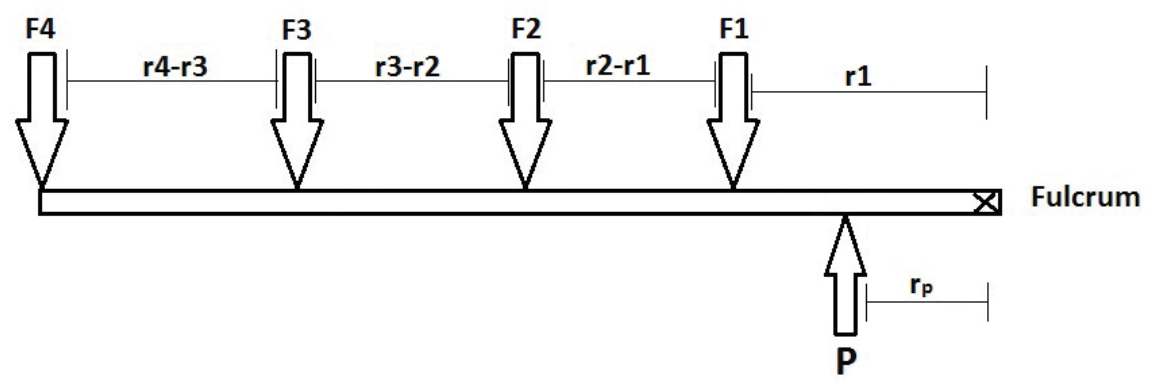

Figure 18: Free body diagram of the lever with four buckets attached. P represents the contact force applied by the top support bar.

To calculate $\mathrm{P}$, the moments acting on the lever in static equilibrium are summed about the fulcrum.

$$
\begin{gathered}
\sum M=0 \\
-F_{1} r_{1}+\left(-F_{2} r_{2}\right)+\left(-F_{3} r_{3}\right)+\left(-F_{4} r_{4}\right)+P r_{p}=0 \\
P=\frac{1}{r_{p}}\left[F_{1} r_{1}+F_{2} r_{2}+F_{3} r_{3}+F_{4} r_{4}\right]
\end{gathered}
$$




\section{Chapter 3}

\section{Results \& Conclusion}

\subsection{Results}

Straw fibers were cut into lengths of $3 \mathrm{~cm}$ and $6 \mathrm{~cm}$. The $3 \mathrm{~cm}$ straw fibers were tested in fractions of $0.25 \%$ and $0.50 \%$ by weight of the dry soil while the $6 \mathrm{~cm}$ straw fibers were only tested at $0.50 \%$ fiber fraction. The bamboo fibers were cut in lengths of $6 \mathrm{~cm}$ and tested in fiber fractions of $0.125 \%, 0.25 \%$ and $0.50 \%$ by weight. Unreinforced baseline bricks were also tested for a comparative measurement.

\subsection{Brick Production Quality}

Table 1 shows quality measures for each type of brick produced. Usable bricks include no-crack, small crack and moderate cracks. Unusable bricks include substantial cracking and completely fractured. 
Table 1: Brick production quality statistics for each type of composite produced.

\begin{tabular}{|c|c|c|c|c|}
\hline Brick Type & $\begin{array}{c}\text { Number of } \\
\text { Samples }\end{array}$ & $\begin{array}{c}\text { No-Crack } \\
\text { (\%) }\end{array}$ & $\begin{array}{c}\text { Total Usable } \\
\text { (\%) }\end{array}$ & $\begin{array}{c}\text { Total Unusable } \\
\text { (\%) }\end{array}$ \\
\hline BASELINE & 105 & 39.14 & 57.57 & 42.42 \\
\hline $\begin{array}{c}\text { 0.25\% 3 CM } \\
\text { STRAW }\end{array}$ & 92 & 35.80 & 82.67 & 17.33 \\
\hline $\begin{array}{c}\text { 0.50\% 3 CM } \\
\text { STRAW }\end{array}$ & 40 & 55.21 & 85.40 & 14.59 \\
\hline $\begin{array}{c}\text { 0.50\% 6 CM } \\
\text { STRAW }\end{array}$ & 81 & 13.32 & 46.25 & 53.75 \\
\hline $\begin{array}{c}\text { 0.125\% 6 CM } \\
\text { BAMBOO }\end{array}$ & 80 & 29.45 & 72.15 & 27.85 \\
\hline $\begin{array}{c}\text { 0.25\% 6 CM } \\
\text { BAMBOO }\end{array}$ & 55 & 46 & 81 & 19 \\
\hline $\begin{array}{c}\text { 0.50\% 6 CM } \\
\text { BAMBOO }\end{array}$ & 58 & 32.93 & 77.48 & 22.52 \\
\hline
\end{tabular}

In general, reinforcing fibers use their high tensile strengths to help distribute the stresses transmitted by the brick matrix. For this reason reinforced bricks have higher strain energy density and lower post-peak strength loss than unreinforced bricks. As a consequence, during failure reinforced bricks demonstrate many small fractures of limited size as opposed to very few fractures of substantial size [8]. Therefore, as fiber fractions increase the number of bricks categorized as unsuable (substantially and completely fractured) should decrease. The results in Table 1 align with this conclusion

The unreinforced baseline bricks had $42.35 \%$ of its sample qualify as unusable due to significant fracturing whereas fiber reinforced bricks as calculated from Table 1 averaged only 20.03\%. Furthermore, of the 105 unreinforced bricks produced, $24.7 \%$ completely fractured during curing. For the 406 fiber reinforced bricks produced, only $2.4 \%$ fractured during curing; two of which were from the $0.25 \% 3$ cm straw bricks and eight from the $0.125 \% 6 \mathrm{~cm}$ bamboo bricks. Such a substantial 
increase in usable brick production could greatly decrease labor time and give the community member more opportunity for other projects.

It should be noted that these trends do not include results from the $0.50 \% 6 \mathrm{~cm}$ straw bricks. These bricks consistently tested far below any other brick and as shown in Table 1 less than half of their sample passed quality standards for testing. Tables 2-4 show that these bricks also consistently performed incredibly poorly in compression tests. Analyzing these bricks during and after production it seemed possible that the composite's fiber fraction reached a volumetric upper limit. Further studies regarding the upper limits of fiber fractions as volumetric proportions are recommended.

\subsection{Compressive Strength}

Tables 2-4 list the results for mean compressive strength in descending order for all tests completed and are organized by brick quality. The compressive strength was calculated to have an uncertainty of $+/-0.22-0.32 \frac{\mathrm{N}}{\mathrm{mm}^{2}}$. This uncertainty is based in the propagation of uncertainties inherent in each of the measurements needed for determining the variables in Equation 1. Methods for calculation followed the customary partial derivative approach given by Holman [40]. Pvalues for two tailed t-tests of 95\% are also listed in Tables 2-4.

Table 2 lists values for no-crack bricks, Table 3 lists both no-crack and small crack bricks while Table 4 lists values for all tested bricks. These groupings were chosen to view the effects of brick fractures on compressive strength. Results show that as expected increasing the number of brick fractures does lower the average compressive strength but not by an extremely significant amount. Scatter plots demonstrating the variation in brick compressive strength for Tables 2-4 can be seen in Figures 19, 21 and 23 respectively. Bar graphs displaying the average compressive strength for each testing sample can be seen in Figures 20, 22 and 24. 
Table 2: Compressive strength of each composite calculated using no-crack bricks only.

\begin{tabular}{|c|c|c|c|c|}
\hline Fibers Tested & $\begin{array}{c}\text { Number of } \\
\text { Samples }\end{array}$ & $\begin{array}{c}\text { Mean Compressive } \\
\text { Strength (N/ mm^2) }\end{array}$ & $\begin{array}{c}\text { Standard } \\
\text { Deviation }\end{array}$ & Two tailed P-values \\
\hline BASELINE & 36 & 1.9496 & 0.2606 & $\mathrm{n} / \mathrm{a}$ \\
\hline $\mathbf{0 . 2 5 \%} 6$ CM BAMBOO & 23 & 1.8982 & 0.2773 & 0.485 \\
\hline $\mathbf{0 . 1 2 5 \%} 6$ CM BAMBOO & 27 & 1.8576 & 0.1959 & 0.120 \\
\hline $\mathbf{0 . 2 5} \% 3$ CM STRAW & 24 & 1.8098 & 0.1881 & 0.021 \\
\hline $\mathbf{0 . 5 0 \% 6 ~ C M ~ B A M B O O ~}$ & 12 & 1.7431 & 0.2809 & 0.038 \\
\hline $\mathbf{0 . 5 0 \% 3 ~ C M ~ S T R A W ~}$ & 16 & 1.6894 & 0.2770 & 0.003 \\
\hline
\end{tabular}




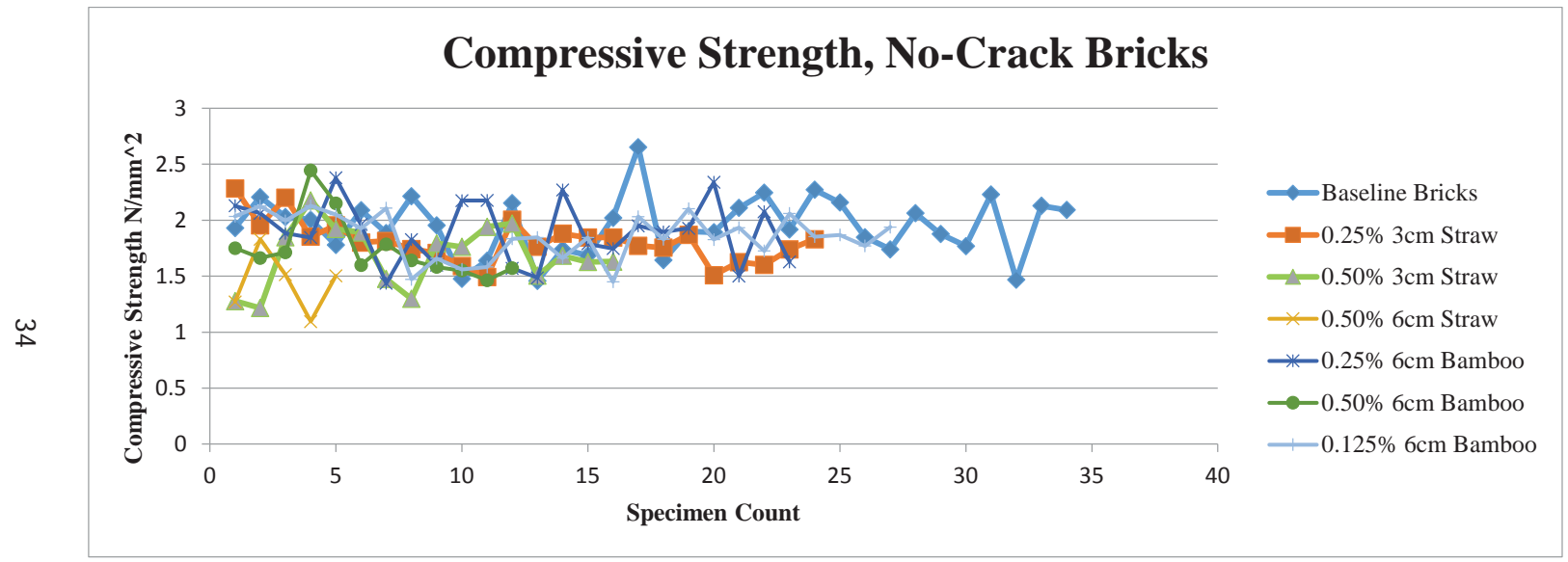

Figure 19: Compressive strength of no-crack bricks. 


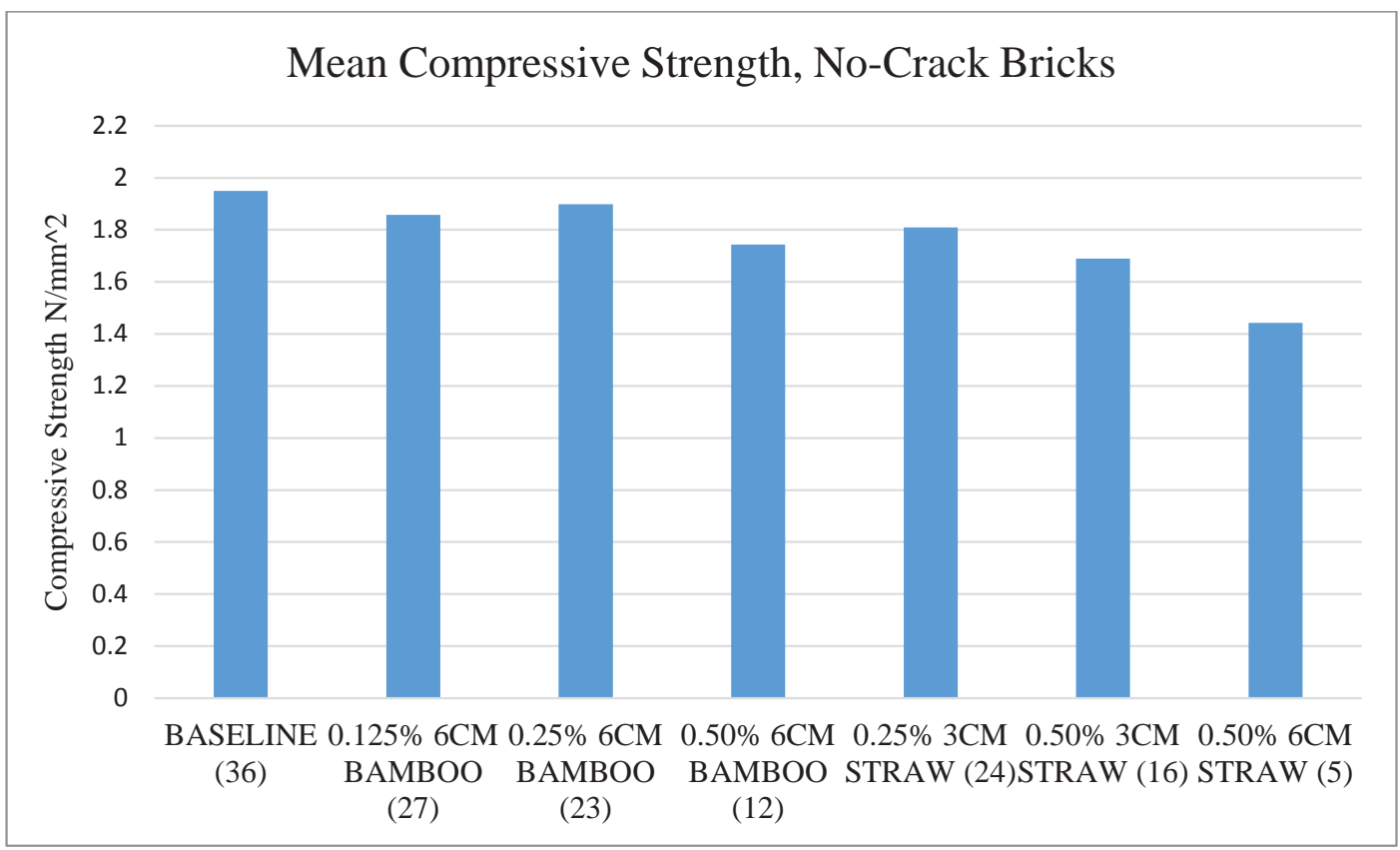

Figure 20: Average compressive strength of no-crack bricks for each testing sample. 
Table 3: Compressive strength of each composite calculated using no-crack and small crack bricks.

\begin{tabular}{|c|c|c|c|c|}
\hline Fibers Tested & $\begin{array}{c}\text { Number of } \\
\text { Samples }\end{array}$ & $\begin{array}{l}\text { Mean Compressive } \\
\text { Strength }\left(\mathrm{N} / \mathrm{mm}^{\wedge} 2\right)\end{array}$ & $\begin{array}{l}\text { Standard } \\
\text { Deviation }\end{array}$ & Two tailed P-values \\
\hline 0.25\% 6 CM ВАМBOO & 31 & 1.8803 & 0.2869 & 0.753 \\
\hline BASELINE & 42 & 1.8581 & 0.3109 & $\mathrm{n} / \mathrm{a}$ \\
\hline 0.125\% 6 СМ ВАМВОО & 38 & 1.8049 & 0.2074 & 0.366 \\
\hline 0.50\% 6 CM ВАМBOО & 20 & 1.6876 & 0.2508 & 0.025 \\
\hline 0.25\% 3 CM STRAW & 48 & 1.6581 & 0.2495 & 0.001 \\
\hline 0.50\% 3 CM STRAW & 23 & 1.5691 & 0.3170 & 0.0009 \\
\hline 0.50\% 6 CM STRAW & 17 & 1.1227 & 0.3275 & $1.24 \mathrm{e}-08$ \\
\hline
\end{tabular}




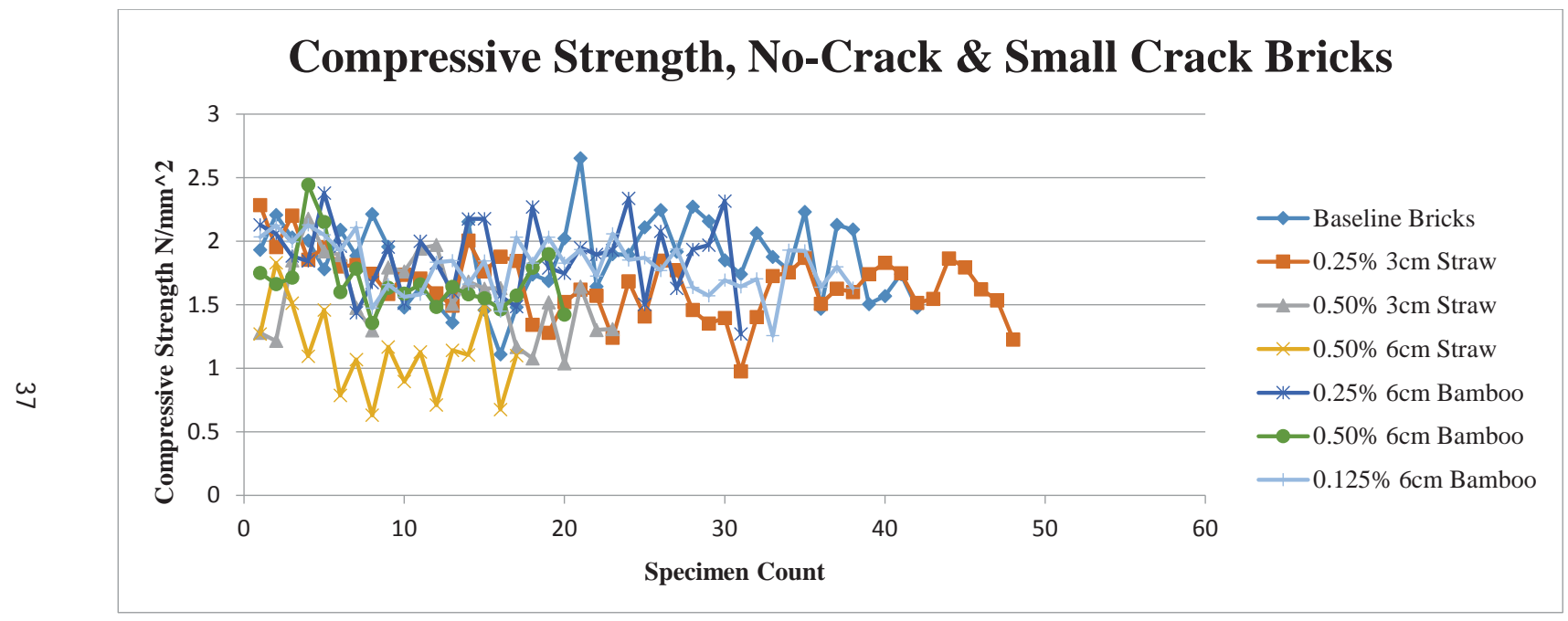

Figure 21: Compressive strength of no-crack and small crack bricks. 


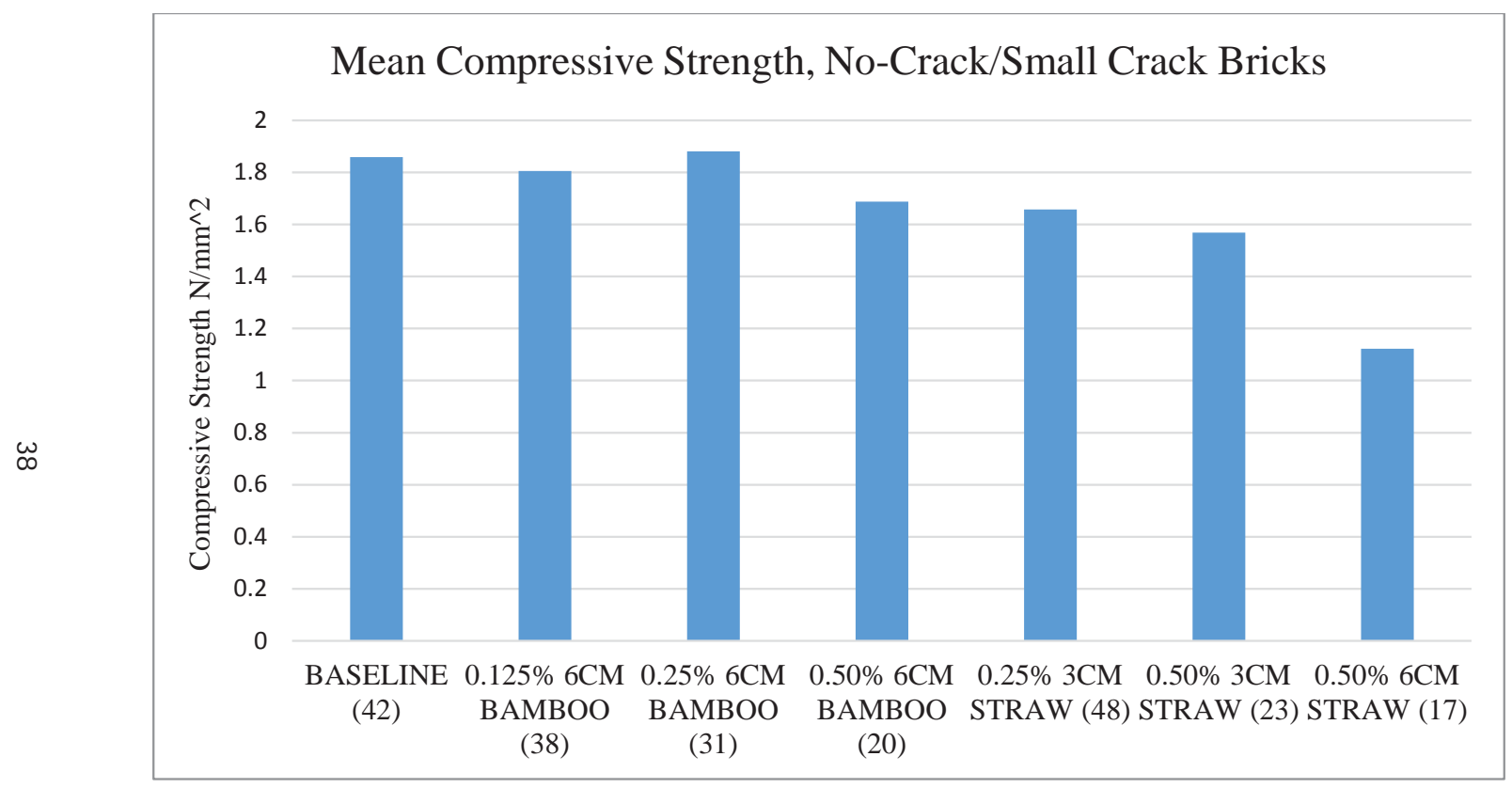

Figure 22: Average compressive strength of no-crack and small crack bricks for each testing sample. 
Table 4: Compressive strength of each composite calculated using all tested bricks. Includes no-crack, small crack and moderate crack bricks.

\begin{tabular}{|c|c|c|c|c|}
\hline Fibers Tested & $\begin{array}{c}\text { Number of } \\
\text { Samples }\end{array}$ & $\begin{array}{c}\text { Mean Compressive } \\
\text { Strength (N/mm^2) }\end{array}$ & $\begin{array}{c}\text { Standard } \\
\text { Deviation }\end{array}$ & Two tailed P-values \\
\hline BASELINE & 53 & 1.8094 & 0.3476 & $\mathrm{n} / \mathrm{a}$ \\
\hline $\mathbf{0 . 1 2 5 \%} 6$ CM BAMBOO & 38 & 1.8049 & 0.2074 & 0.941 \\
\hline $\mathbf{0 . 2 5 \%} 6$ CM BAMBOO & 38 & 1.7998 & 0.3473 & 0.900 \\
\hline $\mathbf{0 . 2 5 \% 3 ~ C M ~ S T R A W ~}$ & 51 & 1.6383 & 0.2741 & 0.004 \\
\hline $\mathbf{0 . 5 0 \% 3 ~ C M ~ S T R A W ~}$ & 28 & 1.4741 & 0.3591 & 0.0002 \\
\hline $\mathbf{0 . 5 0 \% ~ 6 ~ C M ~ B A M B O O ~}$ & 36 & 1.4307 & 0.3990 & $2.54 \mathrm{e}-05$ \\
\hline $\mathbf{0 . 5 0 \%} 6$ CM STRAW & 23 & 0.9955 & 0.3644 & $3.43 \mathrm{e}-11$ \\
\hline
\end{tabular}




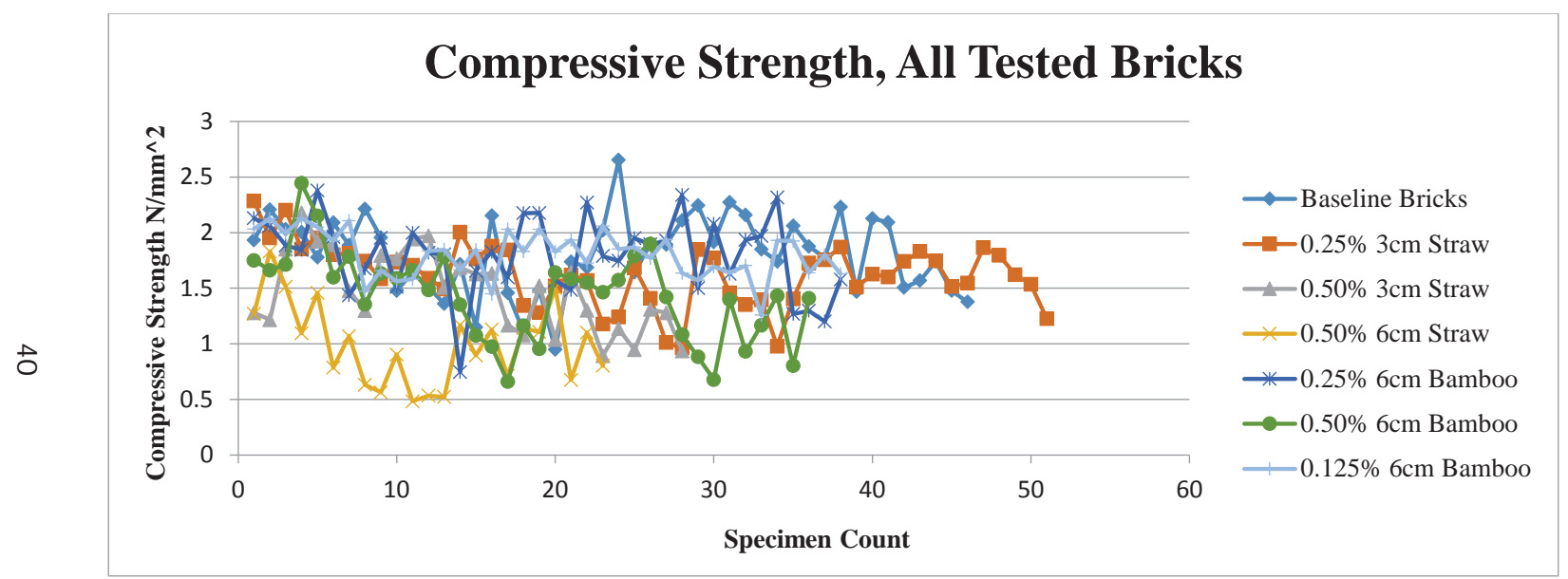

Figure 23: Compressive strength of all bricks tested. 


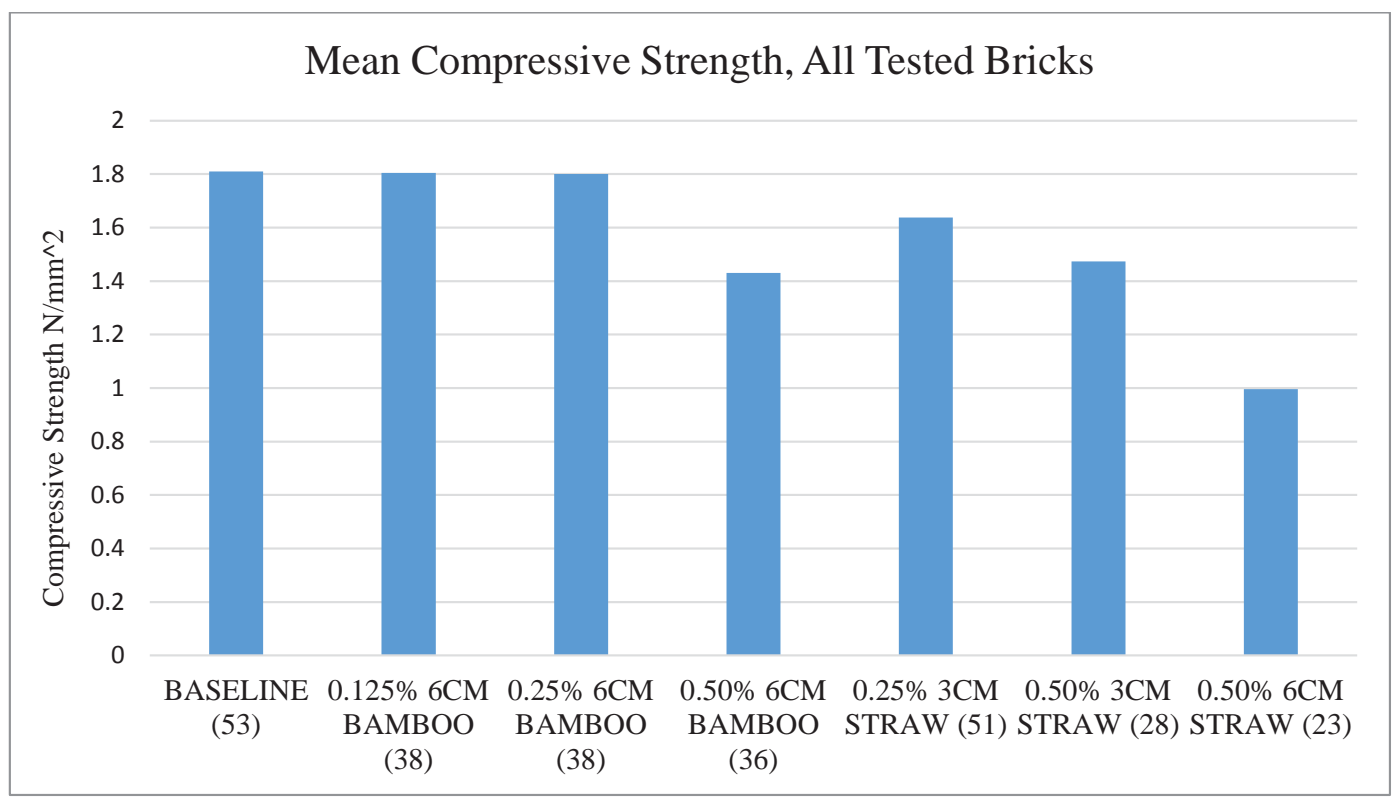

Figure 24: Average compressive strength for all bricks in each testing sample. 
Examining the tables many trends can be identified. The unreinforced baseline bricks consistently attain the highest values for compressive strength regardless of how the bricks are grouped. Bamboo fibers tend to produce a stronger composite than straw but composite strength in general seems to fall with increasing fiber fraction. This can be seen in all three tables in which bricks reinforced with bamboo fiber fractions of $0.25 \%$ and below measured roughly equal to that of the unreinforced brick. Compressive strength then fell as fiber fractions increased or straw was introduced. However, as can be noted from the p-values all fiber reinforced bricks that measured strengths comparable to the baseline bricks are not statistically significant. Therefore the inclusion of bamboo fibers cannot inconclusively be attributed with increasing or decreasing the composite's strength. Only the bricks that measured strengths much lower than the baseline bricks produce p-values that demonstrate statistical significance, i.e. the fibers can be attributed with the decrease in strength. A final observation as noted earlier is that the $0.50 \% 6 \mathrm{~cm}$ straw fiber composite bricks repeatedly demonstrated strength values well below that of any other composite.

These results contradict the conventional findings that reinforcing fibers increase composite strength and lend evidence that under true field conditions reinforcing fibers may actually be detrimental to brick strength. To analyze this it is necessary to take a deeper look at the fiber-matrix interaction.

The failure of reinforcing fibers is governed by fiber pullout, fiber breakage and localized deformations that can arise from non-uniform fiber distribution [13], [41]. Fiber pullout is dictated by the shear strength at the fiber-matrix interface which is directly related to fiber surface friction (fiber roughness), soil cohesion and the difference in water absorption between the fiber and matrix during curing.

The present study was conducted using a very clayey soil which by definition has strong soil cohesion properties and therefore was not the cause for weakness at the interface. Furthermore, both straw and bamboo have sufficiently high moduli of elasticity that fiber breakage can be ruled out. This was confirmed by inspecting bricks that were successfully fractured during testing and not observing any 
broken fibers. Instead, it is suspected that the main influence of composite weakness was due to both the drying conditions and the nonhomogeneous mixing of fibers.

When the matrix and fibers are mixed with water then set to dry they swell and contract. The unequal rates of swelling and contracting between the matrix and fibers can leave voids at the fiber-matrix interface. If the void is sufficiently large (at the micro level) it is clear that there cannot be any shear force at the interface creating perfect conditions for fiber pullout and slippage. Since bricks were left to dry under climatic conditions they were constantly exposed to large fluctuations in both humidity and air pressure which directly affects pore water pressure and drying rate. This continuous fluctuation maintained the matrix and fibers in a constant state of swelling and contracting all the way up to compression testing. For this reason it was attempted to only test bricks after midday when any excess moisture would have had a chance to evaporate. Finally, fiber pullout is also related to the surface friction of the individual fiber material. Bamboo is inherently a much rougher material than straw and would therefore have a higher value of shear strength at the fiber-matrix interface which in turn better utilizes bamboo's high tensile strength. This was supported qualitatively by simply attempting to pull an exposed fiber out of the dried brick matrix. The straw fiber only needed a slight tug with two fingers and dislodged easily. The bamboo fiber could not be dislodged even with the use of pliers. This difference may have been a contributing factor to why bamboo reinforced bricks tested superior to straw reinforced bricks.

A significant problem with mixing fibers within the matrix is achieving a homogeneous mixture. This difficulty exists in the laboratory and is exacerbated under field conditions. The factors associated with non-homogeneous mixtures are typically classified into the unequal distribution of fibers (clumping) and the folding of fibers (balling) [13]. For more rigid fibers such as straw and bamboo, folding is not a key issue but clumping is still pertinent. The clumping of fibers can cause localized deformation planes which will reduce brick strength. To investigate fiber clumping, bricks that were successfully fractured during compression testing were inspected for fiber distribution. It was found that fiber clumping was 
identifiable and there also seemed to be a horizontal preference to fiber organization similar to that observed for fiber reinforced sands prepared by moist tamping[42].

\subsection{Feasibility of 3-point Bending Test}

This study attempted to utilize the 3-point bending test as proposed by [10]. The 3point bending test is said to be a straightforward method for calculating brick compressive strength under field conditions. Through extensive experimentation the author did not find this to be true. The typical stress of $2 \frac{\mathrm{N}}{\mathrm{mm}^{2}}$ necessary to fracture even hand compressed unreinforced mud bricks requires applied forces far too large for simple application, especially when the applied weight must be physically balanced upon a bar. To remedy these issues a lever system was constructed that allowed for the necessary force to be applied. While this method was sufficient in obtaining brick failure it is still impractical for field use. The lever system requires a fulcrum of substantial strength that is impractical as a requirement for field testing.

It is suggested to study the effects of water degradation on overall brick strength and durability. After two years of living within a mud brick community the author has concluded that dry compressive strength is not the principal mechanism responsible for mud brick failure. It is the deterioration from rain weathering coupled with a low compressive strength when wet that causes brick failure.

Natural elements such as rain change the physical composition of the mud brick and must therefore be studied separately from the dry brick until a relationship between dry strength and overall durability when wet is known. It is highly advised to investigate brick erodiblity and fracture propagation under conditions of moisture. It is also advised to define a method for testing a brick's wet compressive strength. Dry compressive strength is necessary to confirm that a brick has the fundamental properties necessary for housing construction. Wet compressive strength can demonstrate the variability of brick strength when exposed to weathering and give a measure of the brick's overall durability. It is already 
advised in the literature that a brick should have a dry to wet compressive strength ratio of two [8]. However, the criteria for wet is undefined and there still do not exist exact methods for obtaining a wet brick under field conditions, nor has this ratio been confirmed. A straightforward approach could be to immerse the brick in water for a short amount of time and weigh it afterward. Continue this process until the difference in consecutive weightings is less than $1 \%$. Changes in brick weight could also be recorded against dry weight to define a state of saturation. Likewise compressive strength can be evaluated at each saturation level.

\subsection{Conclusion}

The present study was conducted in the village of Ribaue located in the Northern Province Nampula of Mozambique. Composite mud bricks were produced using highly clayey soil taken from an active termite hill and reinforced with straw and bamboo fibers. Reinforcing fibers were cut in lengths of $3 \mathrm{~cm}$ and $6 \mathrm{~cm}$ and added in fiber fractions by dry soil weight of $0.125 \%, 0.25 \%$ and $0.50 \%$. Bricks were produced and tested for compressive strength using an applications of the 3-point bending test. Throughout the entire brick production process the composite bricks were categorized by quality based on the number of fractures that appeared during curing. During compression testing successfully fractured bricks were also inspected for fiber breakage and fiber distribution. Based on experimental results it has been concluded that:

- Under true field conditions reinforcing fibers do not increase composite strength. Only a decrease was observed.

- Reinforcing fibers do add to the brick's strain energy density which decreases substantial fracturing during curing and ultimately increases brick production efficiency

- Fiber breakage was not observed for bamboo or straw. Evidence for fiber clumping and a preferred horizontal orientation was observed.

- The 3-point bending test as advised by the literature is not an appropriate method for determining dry compressive strength under field conditions. 
The field of earth construction as applied to community development in underdeveloped nations is a unique discipline in that it requires innovative solutions that can be implemented through simplistic means. The diverse nonuniform conditions in which earth construction is practiced creates a demand for direct field experimentation. The intricately prepared theoretically based laboratory experiments must be traded out for a return to the true iteration and prototype based methods that separate engineering from the pure sciences. The applications of earth construction in rural communities are not as immediately lucrative as those of applications in developed countries and therefore research funding is more difficult to obtain. The general approach to research also involves leaving the comfort and familiarity of controlled laboratory conditions for the unpredictable, dynamic and unknown conditions of the field. However this is where true engineering lives, in the heart of experimentation and in-situ prototyping. Over half the world's population live in homes built from unfired earth and suffer the annual struggles of building deterioration due to weathering and natural degradation. The inability to rely on the security of a home is one of the roots of stagnated development and perpetual poverty. If one constantly needs to spend time repairing something as fundamental to human civilization as the home, then one cannot ever develop other aspects such as food security, health and sanitation or steady income. For these reasons it is imperative that the focus of academic research gives equal support to housing solutions in underdeveloped countries. 


\section{Appendix A}

\section{Experimental Details for Calculating Maximum Dry Density (MDD) at Optimum Moisture Content (OMC)}

Maximum dry density was determined by creating sample molds of sieved soil with various moisture contents. All samples were made from the same mold and thus had a constant volume. Five samples were formed at each moisture content of $14 \%$, $16 \%, 18 \%, 20 \%, 22 \%$ and $24 \%$. Manufactured graduated cylinders were employed to determine the volumes of the water-soil mixture proportions for each moisture content. The sample volumes were molded using a $550 \mathrm{~mm}$ More J am Mixed Fruit container. The volume was confirmed against the manufactured graduated cylinder. Once molded the samples were left indoors at room temperature to dry and measured daily.

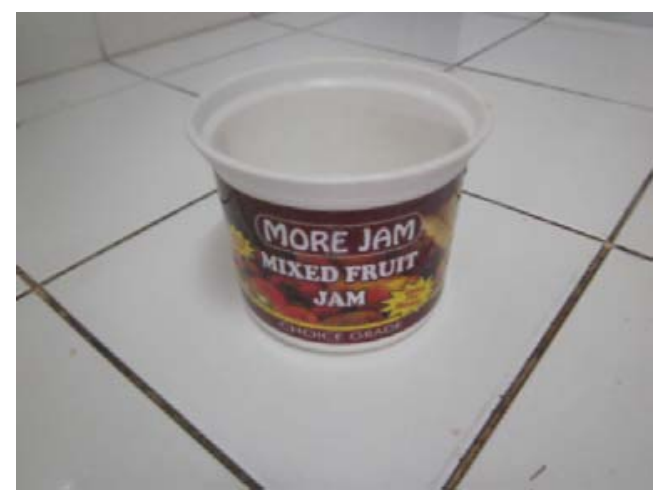

Figure 25: Container used to make MDD volume samples. 


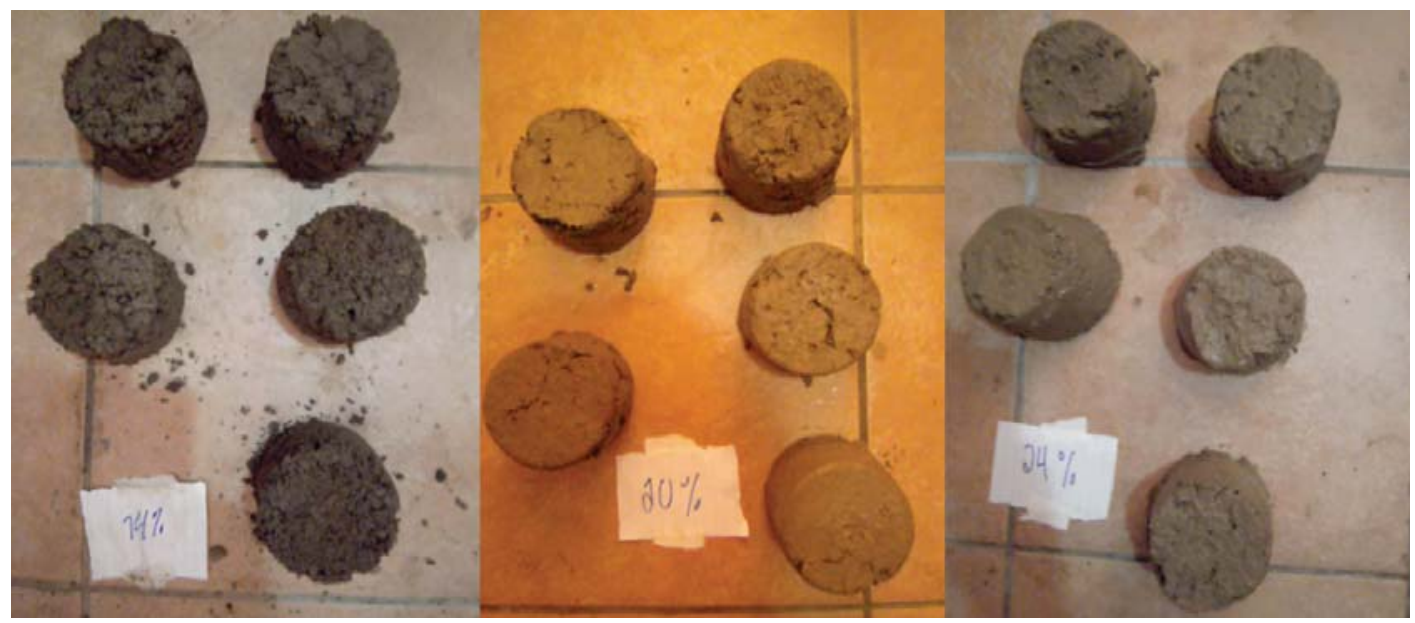

Figure 26: Soil samples molded at various moisture contents. 14\% (left), 20\% (center) and 24\% (right).

The sample volumes were considered dry when the difference between two consecutive measurements showed a difference no greater than the inherent error in the balance (2g). Upon drying the mass of each sample volume was measured and recorded. The mass at each moisture content was determined by taking an average of the five molds. Data is shown in Table 5.

Table 5: Average mass and corresponding moisture content of samples for MDD and OMC testing.

\begin{tabular}{|c|c|}
\hline $\begin{array}{c}\text { Average Mass } \\
\mathbf{( k g )}\end{array}$ & $\begin{array}{c}\text { Moisture Content } \\
\text { (\%) }\end{array}$ \\
\hline 0.655 & 14 \\
\hline 0.6516 & 16 \\
\hline 0.762 & 18 \\
\hline 0.7842 & 20 \\
\hline 0.7686 & 22 \\
\hline 0.7604 & 24 \\
\hline
\end{tabular}

From the graph in Figure 27 we can see that the maximum dry density corresponds to a moisture content of $20 \%$. The curve agrees with those given by [29], [34], [35]. 


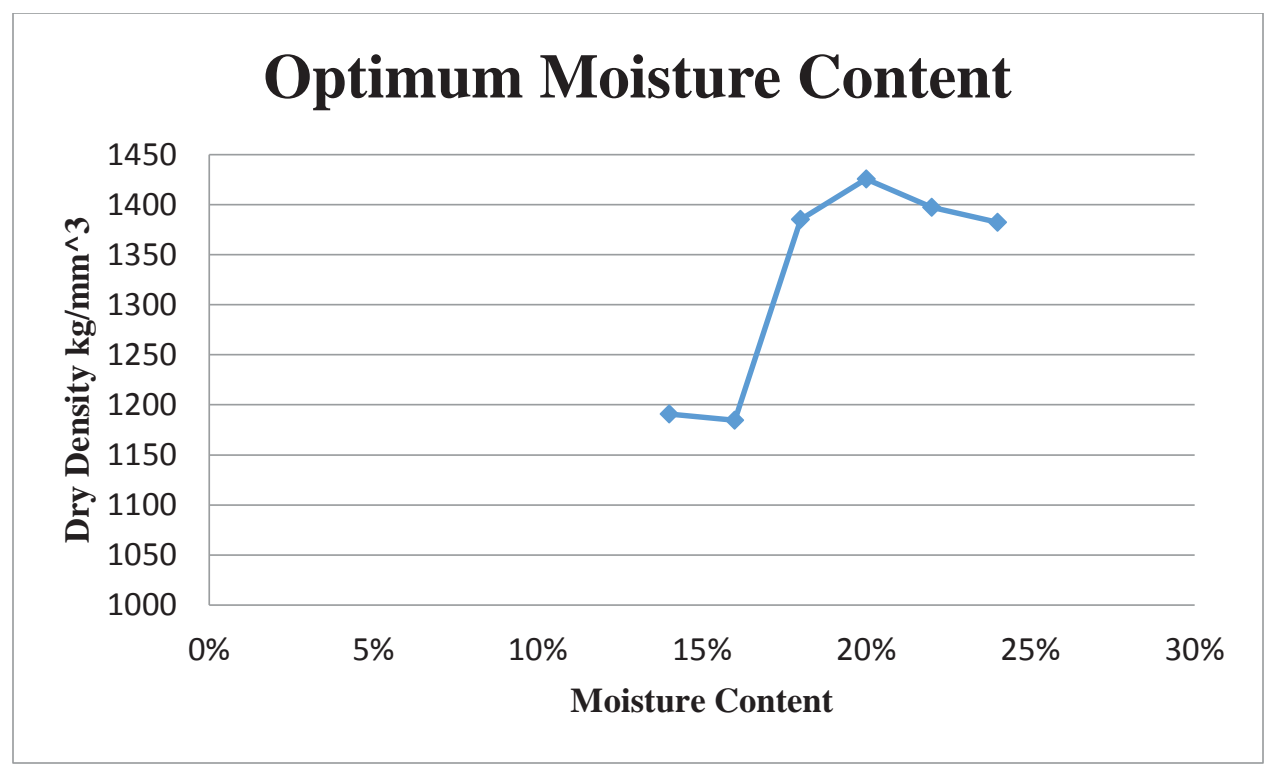

Figure 27: Graph displaying optimum moisture content.

\section{Drop Ball Test and Soil Workability}

The consistency and workability of the mixtures was analyzed at each moisture content. Furthermore, the drop ball test was done to inspect the soil consistency against proposed specifications [7]-[9]. The literature states that upon impact, a soil at the optimum moisture content will break into three or four large pieces, a soil below the optimum moisture content will disintegrate and a soil above the optimum moisture continent will flatten into a pancake. From the experiments executed here which are displayed in Figures 28-30, it is clearly seen that this is not the case. Figure 28 and Figure 29 display water contents below the OMC of $14 \%$ and $16 \%$ respectively. At these moisture contents the soil was still rough and composed of large aggregates. The soil was not incredibly workable or easy to form into volume samples. Upon execution of the drop ball test the soil either crumbled into few pieces or showed very little deformation. 


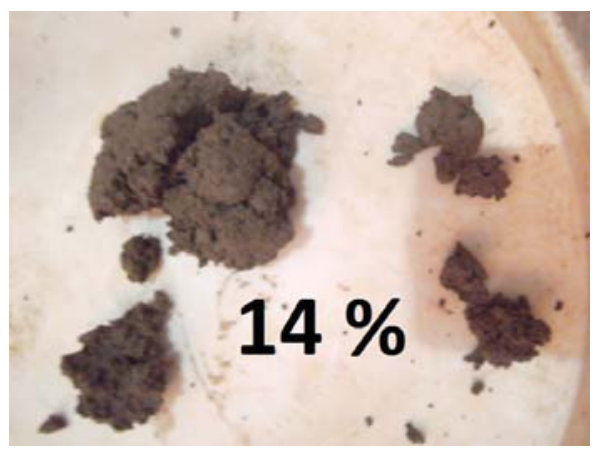

Figure 28: Drop ball test at 14\% moisture content.

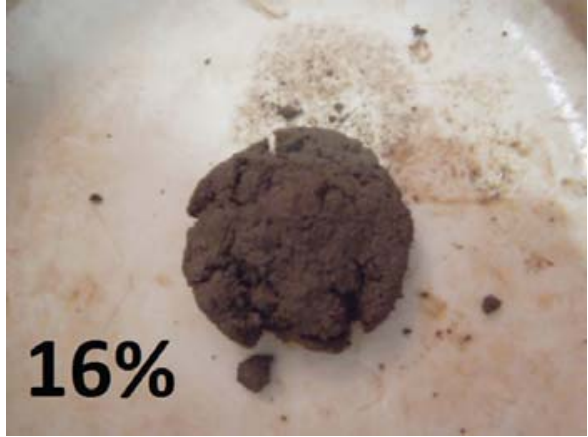

Figure 29: Drop ball test at 16\% moisture content.

At the optimum moisture content of $20 \%$ the soil mixture was smooth, very workable and just near the sticky point. Contrary to the normative documents, the drop ball test did not exhibit a ball that broke into three or four pieces but instead showed a ball that flattened into a pancake. Furthermore, upon impact the ball splattered and did not retain much form.

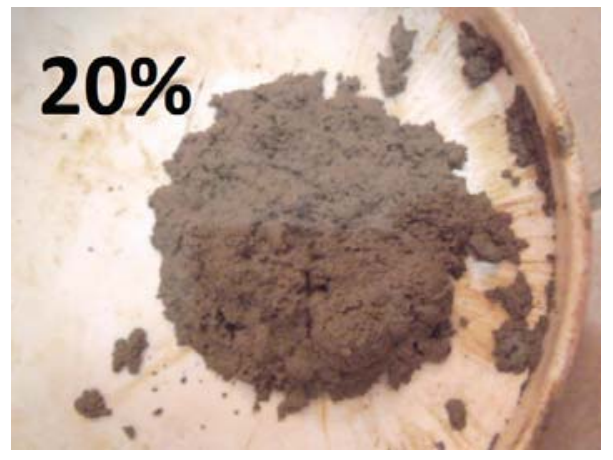

Figure 30: Drop ball test at an OMC of 20\%.

Higher water contents such as $22 \%$ and $24 \%$ were overly moist soils that could be described as 'puddly'. Shown in Figure 31, the drop ball test for a soil at 24\% moisture content completely splattered upon impact. Also, the soils above the OMC did not easily create volume samples. These soils were overly sticky and often took excessive effort to remove from the mold. The impact necessary for extrusion often deformed the volume sample. Some samples slouched upon removal. 


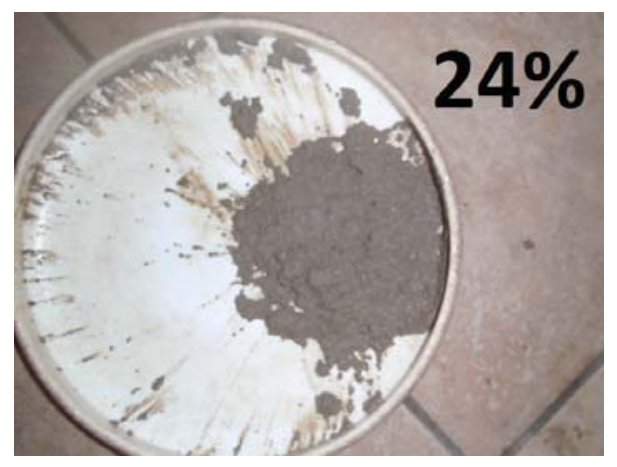

Figure 31: Drop ball test at 24\% moisture content.

\section{Evaluation of Field Tests}

In the pursuit of a field method for calculating brick compressive strength, various other field tests were encountered and experimented with for their usability in the current study. These tests are listed in Section 1.4. Since these tests were not formally evaluated by the author results are not included in the main body. However, useful information regarding their effectiveness can still be gained from the short experimentation that was done. A discussion of each test is given below.

\section{Sedimentation in a bottle}

Sedimentation in a bottle was performed various times on two different soils, one being the very clayey experimental soil and another being a randomly selected sandy soil. Experimental procedure was done following the guidelines given by Adams \&Agib and Rigassi \& Houben [7], [27]. The key difference in the two methods is that the former recommends mixing one part soil to one part water with a teaspoon of common salt and shaking the jar twice while the latter recommends $1 / 4$ soil to $3 / 4$ water, no salt and only shaking once.

After executing this test multiple times across two very different soils, the author did not observe any distribution of soil layers within the jar. While unlikely, there is the possibility that the two soils chosen were entirely clay and entirely sand which would therefore not create layers. It is also possible that the particle 
distribution bandwidth was small enough that a layer distribution was not observable with the naked eye. These claims cannot be refuted without proper laboratory equipment. In either scenario this test did not prove adequate as a field method to determining particle distribution in a soil sample. It is possible that sedimentation in a bottle is only applicable to soils with a large variant in particle distribution.

\section{Cigar test}

The cigar tests was used to gauge soil cohesiveness which can then be used to determine whether a soil has the appropriate silt/ clay content for earth construction. Rigassi \& Houben [27] give the following broken piece lengths

- $\quad<5$ cm soil is too sandy

- $>15 \mathrm{~cm}$ soil is too clayey

- $\quad>5 \mathrm{~cm}$ and $<15 \mathrm{~cm}$ soil is good

The cigar test was performed nine times on the experimental soil which was known to be extremely clayey. Results from the cigar test successfully supported this and are listed in the Table 6. During initial trials of the cigar test it was immediately observed that the broken piece was not equal to the hanging piece. The cigar did not break at the point from which it hung but instead separated further down. For completeness both lengths are listed. 
Table 6: Results from cigar test.

\begin{tabular}{|c|c|}
\hline Hanging Length (cm) & Broken Length $(\mathbf{c m})$ \\
\hline 23 & 18 \\
\hline 22 & 14 \\
\hline 27 & 22 \\
\hline 22 & 22 \\
\hline 22 & 14 \\
\hline 23 & 16 \\
\hline 25 & 20 \\
\hline 25 & 20 \\
\hline 25 & 25 \\
\hline 23.7 & Average \\
\hline & \\
\hline
\end{tabular}

While there does not exist any information in the literature regarding the direct use of the cigar test and its implications for a strong building soil, preliminary tests done by the author find the cigar test to be an appropriate field method for gauging sand vs. clay content.

\section{Wire brush test}

The wire brush test was only performed once on a sample brick not made from the experimental soil but from a different soil with a higher sand content. The weighted wire brush was made by attaching $3 \mathrm{~kg}$ of assorted weights and using electrical tape as shown in Figure 32.

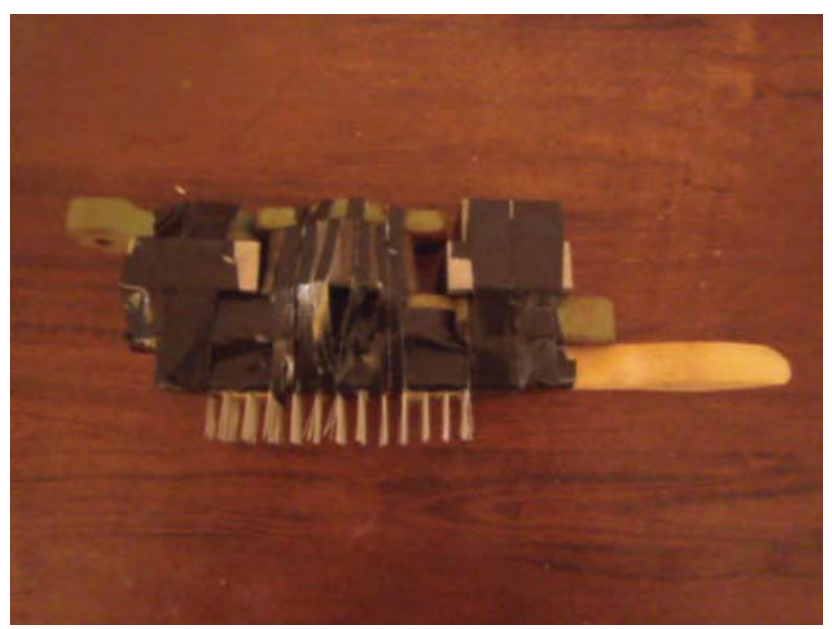

Figure 32: Wire brush with 3kg of weight attached. 
The mass of the brick was recorded before brushing to be $5.158 \mathrm{~kg}$. The brick was then brushed according to the procedure outlined by Adams \& Agib [7] and reweighed afterward at $5.044 \mathrm{~kg}$. Therefore the mass of detached matter as a percentage of initial brick weight was calculated at 2.2\%. An image of the brick after brushing can be seen in Figure 33.

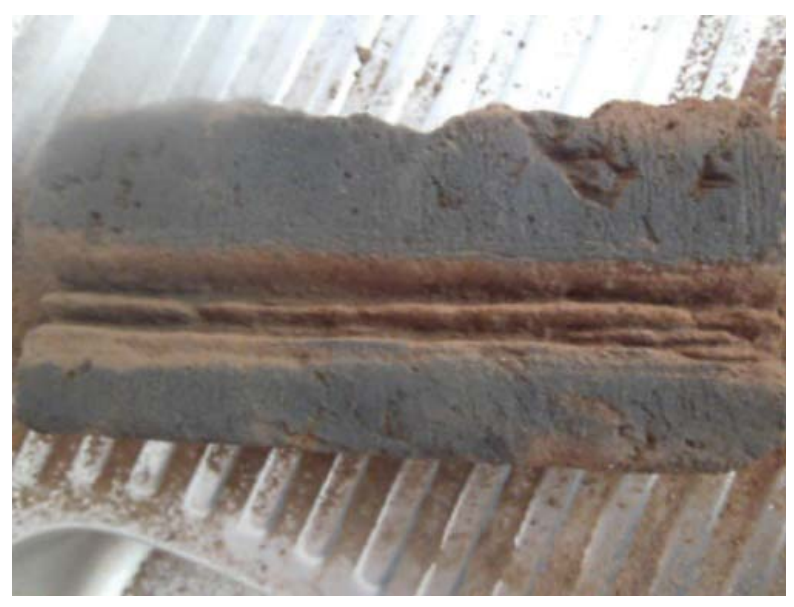

Figure 33: Mud brick after receiving the wire brush test.

The African Regional Organization for Standardization (ARSO) advises that one story homes which are exposed to weather should not have a mass of detached matter that exceeds $10 \%$. From Figure 23 it can be clearly seen that the brick suffered substantial damage from brushing even though it is well below the advised percentage. Therefore it is recommended that the wire brush test be formally evaluated experimentally and the suggested value of $10 \%$ confirmed. Furthermore, other brush factors such as wire gauge and wire quantity are not considered in the proposed test equations and could potentially play a significant role in the percentage of detached matter.

\section{Drip test}

Shown in Figure 34, the drip test was executed by using a plastic water bottle with a slight hole punctured in the cap from a sewing needle. The punctured hole and cap tightness were adjusted as necessary to achieve a drip rate that released 
$100 \mathrm{~mL}$ of water over a 20-60 minute interval. The test brick was elevated to approximately $27^{\circ}$ using another brick.

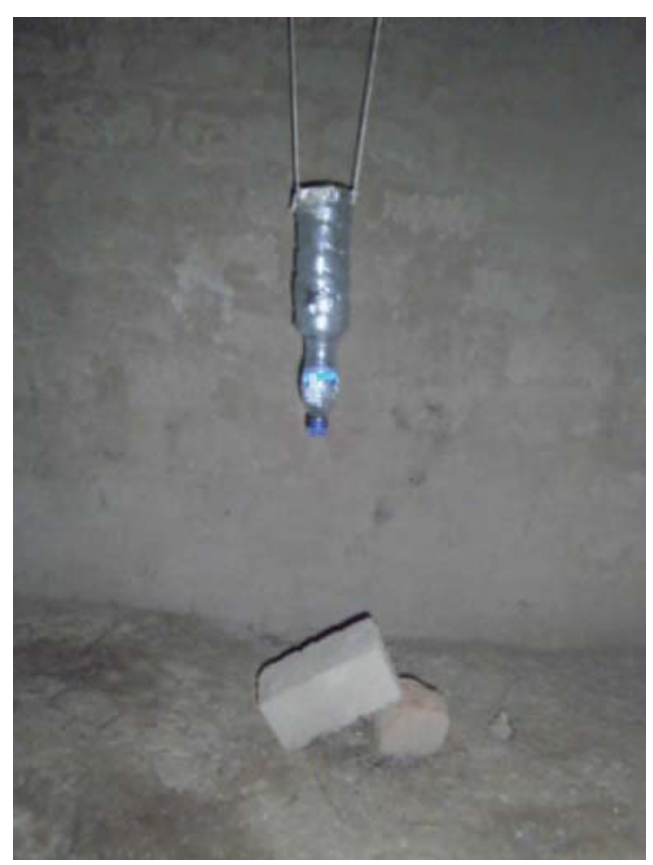

Figure 34: Experimental setup of drip test.

The drip test was performed numerous times on the experimental soil as well as another soil of higher sand content. In both instances there was not any measurable pit depth observed. Using Table 7 as proposed by Frenchman [31] the test brick is rated as non-erosive. Without more experimentation the author cannot make further claims regarding the drip test or these results. However, it appears highly suspicious that a hand-pressed non-stabilized mud brick tests as non-erosive. It is advised that the drip test be thoroughly evaluated.

Table 7: Drip test pit depth ratings.

\begin{tabular}{|c|c|}
\hline Depth of pitting $(\mathbf{m m})$ & Rating \\
\hline 0 & Non-erosive \\
\hline $0<$ and $<5$ & Slightly erosive \\
\hline $5<$ and $<10$ & Erosive \\
\hline$>10$ & Very erosive \\
\hline
\end{tabular}




\section{References}

[1] "Climate Change Knowledge Portal 2.0," The World Bank Group, 1900-2009.

[Online]. Available: http://sdwebx.worldbank.org/climateportal/index.cfm?page=

country_historical_climate\&ThisRegion=Africa\&ThisCCode=MOZ. [Accessed 27 April 2015].

[2] D. Bourdon, Designing the earth: the human impulse to shape nature, Harry N. Abrams, Inc., 1995.

[3] B. Berge, The ecology of building materials, Burlington: Elsevier, Ltd., 2000.

[4] M. C. J. Delgado and I. C. Guerrero, "The selection of soils for unstabilised earth building: A normative review," Construction and Building Materials, vol. 21, pp. 237$251,2007$.

[5] F. Pacheco-Torgal and S. Jalali, "Earth construction: Lessons from the past for future eco-effecient construction," Construction and Building Materials, vol. 29, pp. 512519, 2012.

[6] V. Maniatidis and P. Walker, "A Review for Rammed Earth Construction for DTi Partners in Innovation Project for 'Developing Rammed Earth for UK Housing'," University of Bath, 2003.

[7] E. A. Adam and A. R. A. Agib, Compressed Stabilised Earth Block Manufacture in Sudan, Paris: United Nations Educational, Scientifc and Cultural Organization, 2001.

[8] Q. Piattoni, E. Quagliarini and S. Lenci, "Experimenal analysis and modelling of the mechanical behaviour of earthern bricks," Construction and Building Materials, vol. 25, pp. 2067-2075, 2011.

[9] A. Uchaipichat, "Prediction of shear strength for unsaturated soils under drying and wetting processes," Electronic Journal of Geotechnical Engineering, vol. 15, pp. 1087-1102, 2010. 
[10] J. Morel and A. Pkla, "A model to measure compressive strength of compressed earth blocks with the '3-point bending test'," Construction and Building Materials, vol. 16, pp. 303-310, 2002.

[11] S. Yetgin, O. CAVDAR and A. Cavdar, "The effects of fiber contents on the mechanic properties of the adobes," Constructio and Building Materials, vol. 22, pp. 222-227, 2008.

[12] K. V. Maheshwari, A. K. Desai and C. H. Solanki, "Performance of fiber reinforced clayey soil," Electronic Journal of Geotechnical Engineering, vol. 16, pp. 1067-1082, 2011.

[13] S. M. Hejazi, M. Sheikhzadeh, S. M. Abtahi and A. Zadhoush, "A simple review of soil reinforcement by using natural and synthetic fibers," Construction and Building Materials, vol. 30, pp. 100-116, 2012.

[14] V. Mathur, "Composite materials from local resources," Construction and Building Materials, vol. 20, pp. 470-477, 2006.

[15] K. Ghavami, R. D. Toledo and N. P. Barbosa, "Behaviour of composite soil reinforced with natural fibers," Cement and Concrete Composites, vol. 21, pp. 39-48, 1999.

[16] A. Chegenizadeh and H. Nikraz, "Effective parameters on strength of reinforced clayey sand," International Journal of Material Science, vol. 2, no. 1, pp. 1-5, 2012.

[17] H. Binici, O. Aksogan and T. Shah, "Investigation of fibre reinforced mud brick as a building material," Construction and Building Materials, vol. 19, pp. 313-318, 2005.

[18] M. Bouhicha, F. Aouissi and S. Kenai, "Performance of composite soil reinforced with barley straw," Construction and Building Materials, vol. 27, pp. 617-621, 2005.

[19] R. M. Rowell, J. S. Han and J. S. Rowell, "Characterization and factors effecting fiber properties," in Natural Polymers and Agrofibers Composites, Sao Carlos, Brazil, Embrapa Instrumentacao Agropecuaria, 2000, pp. 115-134.

[20] A. H. Heath, A Manual of Lime and Cement, London: William Clowes and Sons, 1893. 
[21] H. Binici, O. Aksogan, D. Bakbak, H. Kaplan and B. Isik, "Sound insulation of fibre reinforced mud brick walls," Construction and Building Materials, vol. 23, pp. 10531041, 2009.

[22] E. A. Adam and P. J. Jones, "Thermophysical properites of stabilised soil building blocks," Building and Environment, vol. 30, no. 2, pp. 245-253, 1995.

[23] A. Guettala, A. Abibsi and H. Houari, "Durability study of stabilized earth concrete under both laboratory and climatic conditions exposure," Construction and Building Materials, vol. 20, pp. 119-127, 2006.

[24] L. Turanli and A. Saritas, "Strengthening the structural behavior of adobe walls through the use of plaster reinforcement mesh," Construction and Building Materials, vol. 25, pp. 1747-1752, 2011.

[25] K. B. Ren and D. A. Kagi, "Upgrading the durability of mud bricks by impregnation," Building and Environment, vol. 30, no. 3, pp. 433-440, 1995.

[26] R. L. Santoni and S. L. Webster, "Airfields and roads construction using fiber stabilization of sands," Journal of Transportation Engineering, vol. 127, pp. 96-104, 2001.

[27] V. Rigassi and H. Houben, Compressed Eath Blocks: Manual of Production, Deutsches Zentrum fur Entwicklungstechnologien - GATE, 1995.

[28] D. L. Rowell, Soil Science: Methods \& Applications, Essex: Longman Scientific \& Technical, 1994.

[29] H. Houben and H. Guillard, Earth Construction: A Comprehensive Guide, Practical Action, 1994.

[30] P. J. Yttrup, K. Diviny and F. Sottile, "Development of a drip test for the erodability of mud bricks," Deakin University, School of Architecture, 1981.

[31] G. J. Frenchman, "The performance of earth buildings," Deakin University, Geelong, 1982.

[32] S. Boubekeur and H. Houben, Compressed Earth Blocks Standards, Brussels: CDI, CRATerre-EAG/ODA, 1998. 
[33] J.-C. Morel, A. Pkla and P. Walker, "Compressive strength testing of compressed earth blocks," Construction and Building Materials, vol. 21, pp. 303-309, 2007.

[34] A. Kumar, B. S. Walia and J. Mohan, "Compressive strength of fiber reinforced highly compressible clay," Construction and Building Materials, vol. 20, pp. 1063-1068, 2006.

[35] J. K. Newman and D. J. White, "Rapid assessment of cement/fiber stabilized soil using roller-integrated compaction monitoring," in Transportation Research Board 87th Annual Meeting, Washington D.C., 2008.

[36] E. Avrami, H. Guillaud and M. Hardy, Terra literature review: An overview of research in earthen architecture conservation, Los Angeles: The Getty Conservation Institute, 2008.

[37] H. S. Ramaswamy, B. M. Ahuja and S. Krishnamoorthy, "Behaviour of concrete reinforced with jute, coir and bamboo fibers," International Journal of Cement Composites and Lightweight Concrete, vol. 5, no. 1, pp. 3-13, 1983.

[38] L. Elizabeth and C. Adams, Alternative Construction: Contemporary Natural Building Methods, Hoboken: John Wiley \& Sons, 2005.

[39] Woodcraft: A Journal of Woodworking with Which is Incorporated the Patternmaker, Vols. 9-11, 1908.

[40] J. P. Holman, Experimental Methods for Engineers, Tokyo: McGraw-Hill, 1971.

[41] C. Li, "Mechanical response of fiber-reinforced soil," Ph.D Dissertation, Dept. of Mech. Eng., Univ. of Texas, Austin, TX, 2005.

[42] A. Diambra, A. R. Russell, E. Ibraim and D. M. Wood, "Determination of fibre orientation distribution in reinforced sands," Geotechnique, vol. 57, no. 7, pp. 623628, 2007.

[43] S.-S. Park, "Unconfined compressive strength and ductility of fiber-reinforced cemented sand," Construction and Building Materials, vol. 25, pp. 1134-1138, 2011.

[44] T. Kavas, "Use of boron waste as a fluxing agent in production of red mud bricks," Building and Environment, vol. 41, pp. 1779-1783, 2006. 
[45] B. E. Rust, "Beneficial reuse of locally-available waste material as lightweight aggregate in lightweight concrete," M.S. Thesis, Dept. Civil Eng., Mich. Tech. Univ., Houghton, MI, 2014.

[46] F. Wu, G. Li and H.-N. Li, "Strength and stress-strain characteristics of traditional adobe block and masonry," Materials and Structures, vol. 46, pp. 1449-1457, 2013.

[47] H. Niroumand and K. A. Kassim, "Comparison of compressive strength in mud bricks with tire shreds and concrete particles as sustainable materials," Electronic Journal of Geotechnical Engineering, vol. 15, pp. 1151-1158, 2010. 